\title{
Bordetella pertussis in School-Age Children, Adolescents and Adults: A Systematic Review of Epidemiology and Mortality in Europe
}

\author{
Denis Macina $\cdot$ Keith E. Evans
}

Received: June 25, 2021 / Accepted: July 30, 2021 / Published online: August 26, 2021

(C) The Author(s) 2021

\begin{abstract}
Pertussis (whooping cough) epidemics persist globally despite high vaccine coverage among infants and young children. The resurgence of pertussis in high-income countries is partly due to waning vaccine immunity, resulting in a pool of unprotected adolescents and adults. However, pertussis is generally less severe in adolescents and adults, and this difference in presentation means it can often be unrecognised by healthcare professionals, meaning that it is largely under-diagnosed in older populations. A systematic search of MEDLINE, EMBASE and BIOSIS was undertaken to identify studies published between 1 January 1990 and 17 June 2019, with information on pertussis epidemiology and mortality in school-aged children, adolescents and adults in Europe. A formal statistical comparison (e.g. using meta-analyses) was not possible because of the mix of methodologies reported. There were 69
\end{abstract}

Supplementary Information The online version contains supplementary material available at https:// doi.org/10.1007/s40121-021-00520-9.

D. Macina $(\square)$

Vaccines Epidemiology and Modelling, Sanofi Pasteur, 14 Espace Henry Vallée, 69007 Lyon, France e-mail: Denis.Macina@sanofi.com

K. E. Evans

inScience Communications, Chowley Oak Business

Park, Chowley Oak Lane, Tattenhall, Cheshire, UK epidemiological studies and 19 mortality studies identified for review. Over the past decade, the reported incidence of notified pertussis cases varied widely between European countries, which is likely associated with differences in surveillance systems, diagnostic techniques and reporting regulations. However, several studies show that pertussis is circulating among adolescents and adults in Europe, and although pertussis-related morbidity and mortality are highest in infants, there is evidence that adults aged $>50$ years are at increased risk. For example, in a hospital-based surveillance study in Portugal, between 2000 and 2015, 94\% of hospitalised pertussis cases were infants aged $<1$ year, with a case fatality rate (CFR) of $0.8 \%$; however, among hospitalised adult cases of pertussis, the CFRs were $11.5 \%$ (aged 18-64 years) and $17.4 \%$ (aged $>65$ years). Very few European countries currently include pertussis boosters for adults in the national immunisation strategy. In addition to increasing pertussis vaccination coverage in adolescents and adults, mitigation strategies in European countries should include improved diagnosis and treatment in these populations.

Keywords: Pertussis; Whooping cough; Epidemiology; Burden; Children; Adolescents; Adults; Europe 


\section{Key Summary Points}

A systematic search was undertaken to identify information on pertussis epidemiology and mortality in schoolaged children, adolescents and adults in Europe.

There were 69 epidemiological studies and 19 mortality studies identified for review.

Over the past decade, the reported incidence of notified pertussis cases varied widely between European countries, However, several studies show that pertussis is circulating among adolescents and adults in Europe, and although pertussis-related morbidity and mortality are highest in infants, there is evidence that adults aged $>50$ years are at increased risk.

Very few European countries currently include pertussis boosters for adults in the national immunisation strategy. In addition to increasing pertussis vaccination coverage in adolescents and adults, mitigation strategies in European countries should include improved diagnosis and treatment in these populations.

\section{INTRODUCTION}

Bordetella pertussis is a highly contagious pathogen that is transmitted in aerosol droplets during coughing and sneezing. Historically, whooping cough, caused by $B$. pertussis infection, was a leading cause of death in young children and mass vaccination over the past 50 years has resulted in a large decline in global prevalence [1]. In most high-income countries, the national immunisation programme (NIP) includes a five-dose diphtheria-tetanus-acellular pertussis (DTaP) schedule for infants, toddlers and pre-school children, with coverage rates of $>95 \%$ [1]. Despite this, pertussis has reemerged in several developed countries, representing a major public health concern [2]. Over the past 10 years, epidemic outbreaks of pertussis have been observed every $3-5$ years, and between 2008 and 2015 there were sizeable spikes in pertussis cases in various countries, including the US, Canada, Australia, the UK, The Netherlands and Japan [3-7].

The resurgence of pertussis in countries with high vaccination coverage has been hypothesised to result from various factors, such as: the differential immunity and durability of responses elicited by acellular (aP) compared with whole-cell (wP) pertussis vaccines; linked-epitope suppression reducing the scope of epitopes involved in $B$. pertussis clearance to vaccine antigens; antigen imbalance with high predominance of PT; an epidemiologic shift resulting from waning of immunity in older children adolescents and adults; improved reporting systems and diagnostic methods; and a possible shift in circulation of the pathogen in pertactin-native strains $[2,8]$.

Although the highest burden of severe cases is among unvaccinated or partly vaccinated infants, epidemiological studies over the past 2 decades in various countries show that there has been a gradual shift in the age-specific peak of notified pertussis cases away from young children and towards adolescents and adults [9]. However, pertussis is often not suspected in older children and adults, leaving highly contagious individuals to spread infection via aerosol droplets for about 21 days after the onset of cough [10]. During pertussis outbreaks in several countries in 2012, whereas infants were the most affected age group, the proportion of affected adults was often much higher compared with recent years, indicating that adults play a major part in the transmission dynamic [11].

To evaluate the epidemiology, burden and mortality of pertussis infection in older children, adolescents and adults in European countries, we performed a systematic literature search and review of published studies of pertussis infection. 


\section{METHODS}

A systematic search of the literature was conducted using EMBASE, Medline and BIOSIS on 17 June 2019 to identify articles about the global epidemiology and mortality of pertussis. Citations were limited to those in English language, in humans and published since 1 January 1990. Terms used in the database searches are shown in Supplement 1 . Web searches were also performed to identify relevant data from governmental, national or regulatory websites and from non-government organisations (Supplement 2).

The areas of interest were epidemiology and sero-epidemiology and pertussis-related mortality and case fatality rates (CFRs). Papers were excluded if they contained: no data of relevance (e.g. not a pertussis study); no data which could be categorised by age groups; a study of pertussis vaccination (e.g. adverse events related to the vaccine); single subject design (e.g. case studies); contained no primary data (in these cases, reference lists were checked and potentially useful papers not identified in the original search were obtained for assessment); and based on a model (either economic or epidemiological), which included no epidemiology source for the calculations or were based on a publication already included in the search.

The review included publications with data for school-aged children, adolescents and adults. The objective was to review the epidemiology and mortality of pertussis by age. In the absence of standardised definitions, we categorised them by the following groups: young children (aged 4-9 years), adolescents (aged $10-18$ years), adults (aged $\geq 19$ years) and older adults (aged $\geq 60$ years).

A total of 2190 citations were identified for the global review of epidemiology and burden. Following an initial review, 763 papers (35\% of the original search) were obtained for full assessment of the inclusion criteria. The search results and reasons for exclusion are shown in Supplement 3. A total of 1421 citations were identified for the global review of mortality. Following an initial review, 331 papers (23\% of the original search) were obtained for full assessment of the inclusion criteria. The search results and reasons for exclusion are shown in Supplement 4.

The systematic review was conducted to assess pertussis globally, and the results for Asia, the Middle East and Africa, are provided as parallel publications. The search results for the global analysis are shown in Supplement 3. This paper provides the results of articles identified with relevant data from countries in Europe.

\section{Serological Thresholds for Infection}

Polymerase chain reaction (PCR), culture and serology using immunoglobulin G (IgG)-based enzyme-linked immunosorbent assays (ELISAs) are laboratory methods used to diagnose pertussis. An international consensus meeting in 2007 recommended that pertussis toxin (PT) should be used as the test antigen and that the results should be expressed in international units (IU/ml) using World Health Organisation (WHO) international standards $[12,13]$.

A four-fold increase in anti-PT IgG concentration between samples is accepted as evidence of recent infection, yet there is currently no global consensus on cutoff thresholds for singlesample serology. The thresholds for anti-PT IgG seropositivity are usually defined based on the manufacturer's instructions for the ELISA test as well as previous experience [14-16]. In individuals who have not been vaccinated within 1 year of the serum sample, anti-PT IgG $\geq 62.5 \mathrm{IU} / \mathrm{ml}$ to $\geq 80 \mathrm{IU} / \mathrm{ml}$ is often used as the cutoff threshold indicating pertussis infection within 12 months and cutoffs of $\geq 100 \mathrm{IU} /$ $\mathrm{ml}$ and $\geq 125 \mathrm{IU} / \mathrm{ml}$ as evidence of recent infection and acute infection, respectively $[13,17,18]$.

\section{Compliance with Ethics Guidelines}

This article is based on previously conducted studies and does not contain any new studies with human participants or animals performed by any of the authors. 


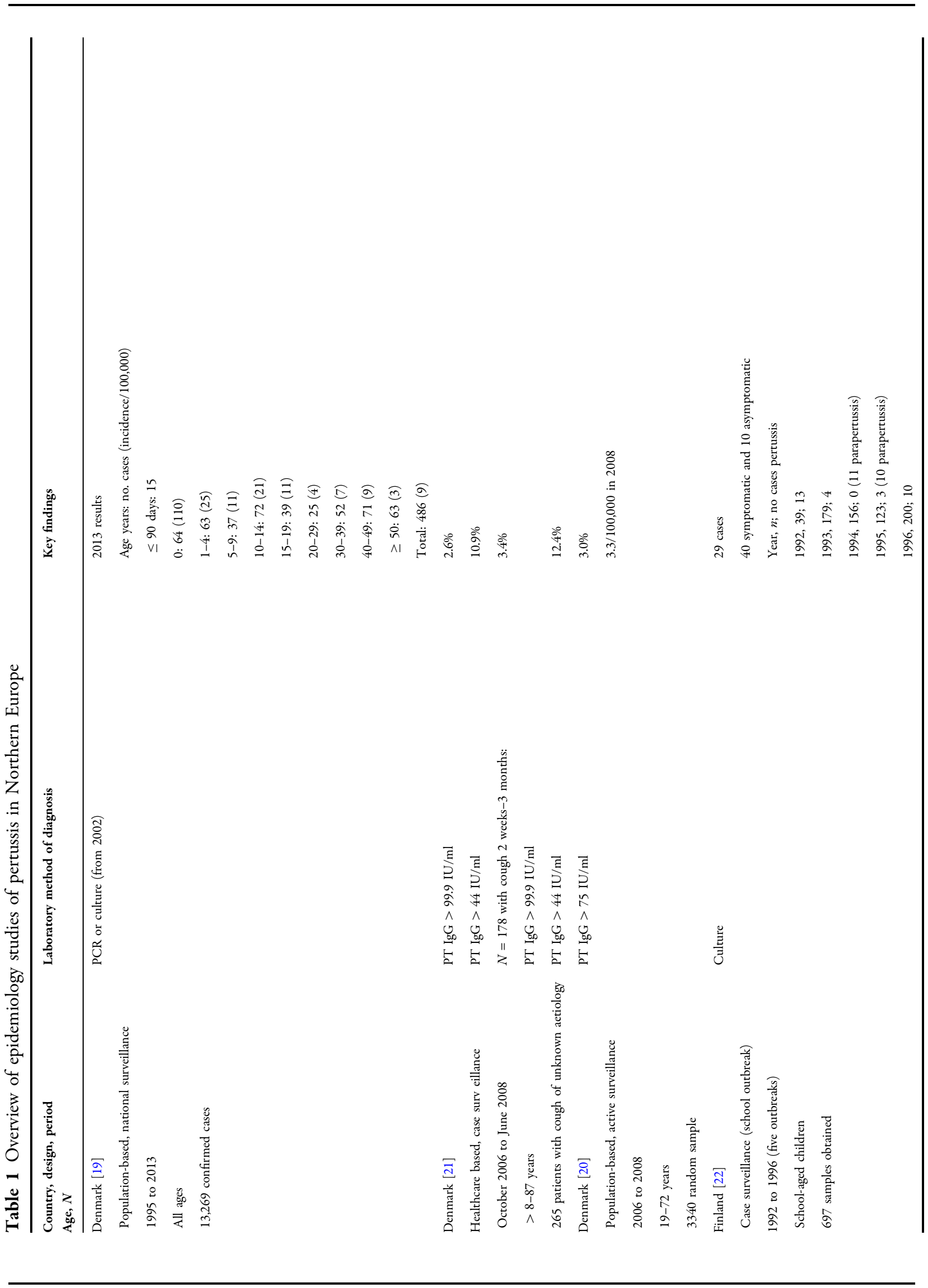




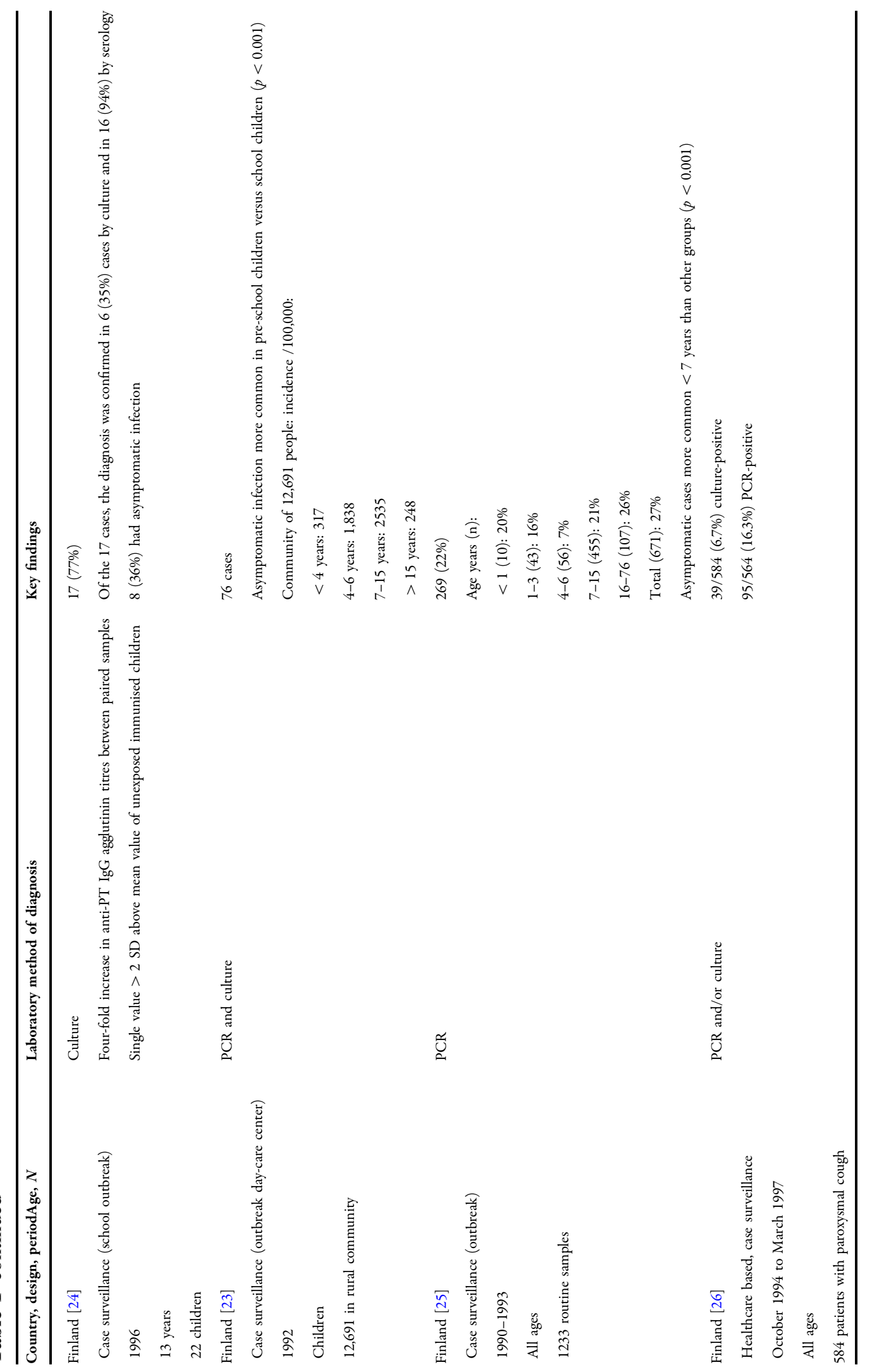




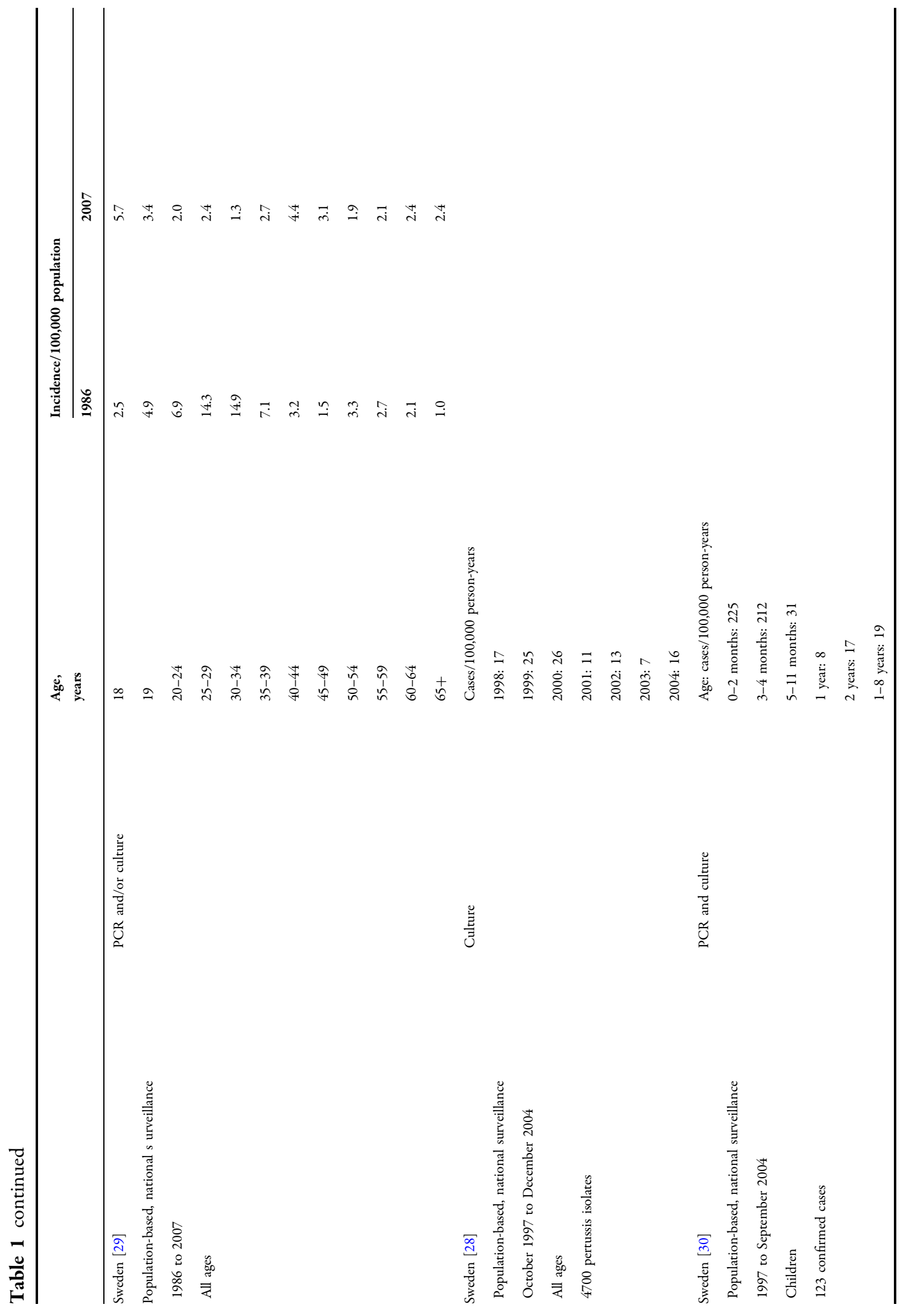




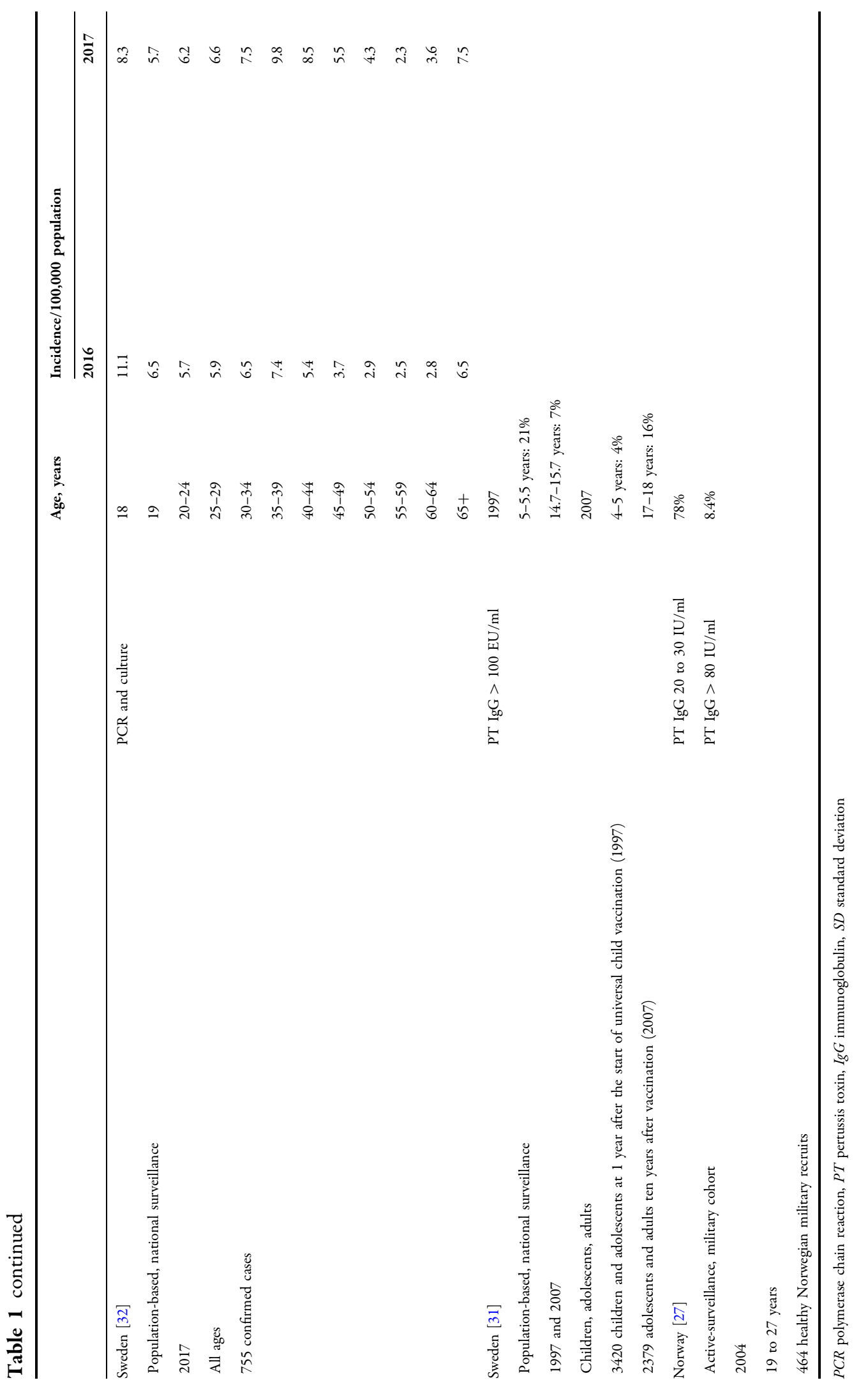




\section{EPIDEMIOLOGY}

\section{Northern Europe}

An overview of epidemiology studies in Northern European countries is shown in Table 1. Data were included from studies in Denmark [19-21], Finland [22-26], Norway [27] and Sweden [28-32].

\section{Denmark}

In Denmark, the National Immunisation Programme (NIP) includes diphtheria-tetanusacellular pertussis (DTaP) at 3, 5, 12 months and 5-7 years [33]. The pre-school booster was introduced in 2003, and a booster dose was introduced for adolescents aged 15-18 years circa 2013. There were three epidemiological studies identified for Denmark. In a study between 1995 and 2013, there were 13,269 PCR/culture-confirmed cases, and in 1995, 80\% of all cases were children aged $<10$ years, but in 2013 , this figure had decreased to $34 \%$. Similarly, in 1995, adults aged $\geq 20$ years accounted for $14 \%$ of all cases but this figure increased to $43 \%$ in 2013 . The median age of PCR/cultureconfirmed cases gradually increased from 5.1 years in 1995 (interquartile range [IQR]: $1.5-8.7$ ) to 15.7 years in 2013 (IQR: 4.8-41.5). Moreover, after the introduction of the preschool booster, the age-specific peak shifted gradually towards older children [19]. In 1995-1997, the age-specific peak of infection was among children aged 3-5 years, yet in 2011-2013, the peak was among children aged 12-14 years [19]. In a population-based, active surveillance study of 3340 Danish adults in 2008, 3.0\% had anti-PT IgG > IgG > $75 \mathrm{IU} / \mathrm{ml}$, at an incidence of 3.3/100,000 [21]. In another study from 2006 to 2008, among 265 patients with cough of unknown aetiology, $2.6 \%$ had anti-PT IgG $>99.9 \mathrm{IU} / \mathrm{ml}$, and among 178 patients with cough for $>3$ months, $3.4 \%$ had anti-PT IgG > $99.9 \mathrm{IU} / \mathrm{ml}[20]$.

\section{Finland}

In Finland, the NIP includes DTaP at 3, 5, 12 months and 4 years and an aP booster at 14-15 years [34]. All of the studies identified for
Finland provided data from 1990 to 1997, i.e. before the introduction of a booster dose for school-aged children. The most recent analysis was a population-based, case-surveillance study conducted between 1994 and 1997, which showed that among 594 patients with paroxysmal cough (age ranged from 7 days to 74 years), $16.3 \%$ had PCR-confirmed pertussis [26]. In a school outbreak in Finland in 1996, among 22 children aged 13 years, 16 (94\%) had positive serology (culture or paired sera), and (36\%) had asymptomatic infection [24].

\section{Sweden}

In Sweden, DTaP vaccines were introduced in 1996, administered at 3, 5 and 12 months. After the switch from wP to aP, the Public Health Agency of Sweden started to conduct enhanced surveillance to assess the effect of pertussis vaccinations on epidemiology and disease severity and to assess long-term protection with aP-containing combination vaccines [32]. The 20-year report from the Public Health Agency of Sweden includes surveillance data from 1996 to 2017 and shows that the incidence of pertussis decreased among groups targeted for vaccination and that during the epidemic years of 2014 and 2015 there was a threefold increase in the incidence of pertussis across all age groups and three infant deaths [32]. The incidence of pertussis across the general population was 7.1/ 100,000 person-years in $2014,5.9 / 100,000$ person-years in $2015,6.5 / 100,000$ person-years in 2016 and 7.5/100,000 person-years in 2017 [32]. Enhanced surveillance in Sweden showed that after the introduction of the aP primary vaccination schedule in 1996, the peak incidence of pertussis shifted from young children towards school-aged children in whom vaccine protection had waned, resulting in the introduction of a booster dose for children aged $4-5$ years in 2007. Following this, the peak incidence of pertussis shifted to children aged $16-17$ years, and in 2016, a Tdap booster dose was introduced to the NIP for adolescents. In 2017, based on 755 laboratory-confirmed cases among all ages, the largest increase in incidence compared with the previous year was among adults aged $>40$ years (from 194 to 265 cases). Between 2016 and 2017, there was a decrease in 
Table 2 Overview of epidemiology studies of pertussis in Western Europe

\begin{tabular}{|c|c|c|}
\hline $\begin{array}{l}\text { Country, design, period } \\
\text { Age, N }\end{array}$ & Laboratory method of diagnosis & Key findings \\
\hline Austria [35] & PCR, culture, ELISA/seroconversion (paired sera) & 71 Incidence/100,000: \\
\hline Hospital-based, case surveillance & & $<5$ years: 2,385 \\
\hline November 1995 to December 1998 & & $6-10$ years: 1841 \\
\hline$<16$ years & & $11-16$ years: 302 \\
\hline \multicolumn{3}{|l|}{184 suspected cases } \\
\hline Belgium [36] & PCR, culture, & 208 in 2008 \\
\hline $\begin{array}{l}\text { Population-based, national surveillance } \\
2008-2012\end{array}$ & or fourfold rise in sera antibody titre & $\begin{array}{l}356 \text { in } 2012(71 \% \\
\text { increase })\end{array}$ \\
\hline $\begin{array}{l}\text { All ages } \\
342 \text { notified cases }\end{array}$ & & $\begin{array}{l}181 \text { cases were in } \\
\text { children } \\
\text { aged }>5 \text { years }\end{array}$ \\
\hline Belgium [38] & PT $\operatorname{IgG}>50 \mathrm{IU} / \mathrm{ml}$ & $n(\%)$ \\
\hline Population-based, active surveillance & & E. Flanders: 8 (6.7) \\
\hline 2012 & & W. Flanders: $13(10.2)$ \\
\hline $20-29.9$ years & & Liege: 4 (3.2) \\
\hline \multirow[t]{3}{*}{670 leftover serum samples } & & Hainaut: $8(13.1)$ \\
\hline & & Brussel: 6 (4.8) \\
\hline & & Bruxelles: 7 (6.0) \\
\hline Belgium [37] & PT $\operatorname{IgG}>100 \mathrm{IU} / \mathrm{ml}$ & $n$ \\
\hline Population-based, active surveillance & & E. Flanders: 16 \\
\hline 2012 & & W. Flanders: 11 \\
\hline $20-39$ years & & Liege: 6 \\
\hline \multirow[t]{3}{*}{1500 left over serum samples } & & Hainaut: 14 \\
\hline & & UZ Brussels: 5 \\
\hline & & CHU Bruxelles: 9 \\
\hline France $[41]$ & PCR & Incidence/100,000 \\
\hline Healthcare based, case surveillance & & 103.6 (crude) \\
\hline June 2013 to August 2014 & & 187.1 (extrapolated) \\
\hline \multicolumn{3}{|l|}{$>50$ years } \\
\hline 129 suspected cases (cough 7-21 days) & & \\
\hline
\end{tabular}


Table 2 continued

Country, design, periodAge, $\mathrm{N}$

France [43]

Healthcare based, case surveillance

June 2013 to August 2014

$>50$ years

129 suspected cases (cough 7-21 days)

France [42]

Case surveillance (outbreak hospital)

July 1997

Adults

59 HCWs

France [40]

Population-based, national surveillance

2000-2005

All ages

595 cases

France [44]

Healthcare based, case surveillance

March and December 1999

Mean 42 years

127 patients with cough $<7$ days

\section{Laboratory method of diagnosis}

PCR

Key findings

Incidence $/ 100,000$

50 years: 187.1

Large cities: 131.1

Medium cities: 256.1

Rural: 187.1

PCR, culture,

$10(17 \%)$
PCR, culture, or serology

Aged 0-15 years: 20 cluster cases; 2 sporadic cases; 175 cases outside of healthcare

Aged > 15 years: 228 cluster cases; 2 sporadic cases; 101 cases outside of healthcare

PCR and/or a significant increase or decrease in anti-PT IgG between acute and convalescent sera

$70 / 183$ confirmed cases; 32\% (95\% CI: 26-39)

PCR-positive: 36

Confirmed: 40 
Table 2 continued

\section{Country, design, periodAge, $\mathrm{N}$}

France [46]

Population-based, active sero-surveillance

June to December 2005

18-60 years

331 travellers attending vaccination clinic

\section{Laboratory method of diagnosis}

PT IgG 20-124 IU/ml

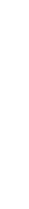

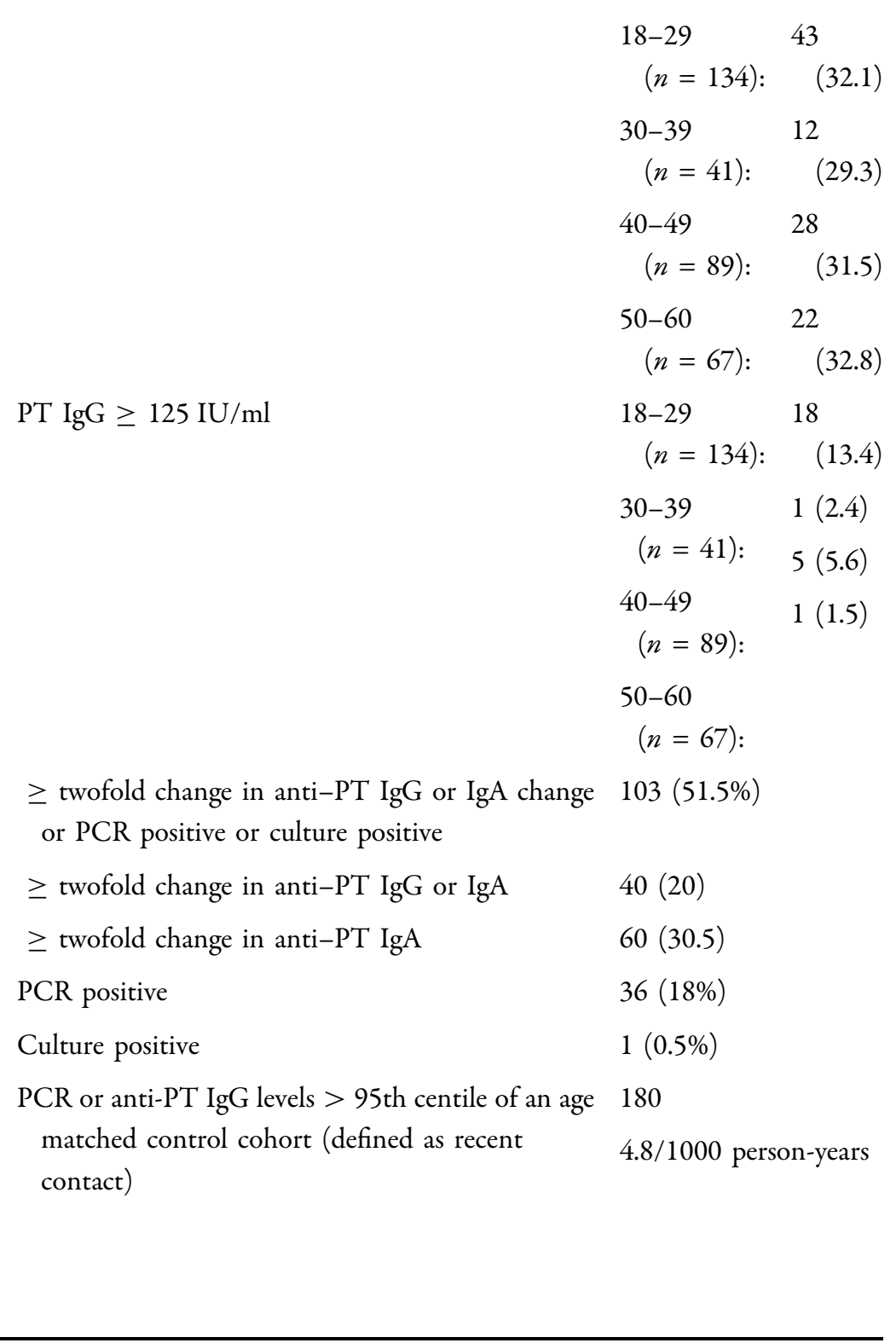

France [45]

Healthcare-based, case surveillance

April to December 1999

$18-88$ years

217 with persistent cough

Germany [47]

Population-based, active surveillance

February 1993 to May 1995

Children

\section{Key findings}

Age years

Cases

(\%) 
Table 2 continued

Country, design, periodAge, $\mathrm{N}$

Germany [48]

Case surveillance (outbreak)

2005

Adults and children

75 cases in US military

Germany [74]

Population based, case surveillance

1992-1994

Children and adults

122 households with index case

Germany [49]

Population based, case surveillance

1984-1987

Adults

1260 cases with pertussis symptoms

Germany [50]

Case surveillance (school outbreak)

October 2005 to March 2006

Children

104 cases

\section{Germany [51]}

Five former East German States

Population-based, national surveillance

\section{Laboratory method of diagnosis}

PCR, culture, or clinical case with epidemiological link to a confirmed case

Key findings

Age: cases (\%)

$<2$ months-4: 11

5-9: 19 (25)

10-14: 20 (27)

15-19: 7 (9)

$\geq 20: 18(24)$

Culture or

84 cases adults

Anti-PT, anti-FHA or anti-pertactin levels increase 179 cases children by $100 \%$

Culture, anti-PT IgA titres $\geq 100$ negative controls

567 confirmed (45\%)

Aged $<1$ year, 324

cases $(11 \%)$

Aged $>20$ years 169

$(6 \%)$

PCR, culture, or anti-IgG levels (cutoff not stated) Years since last vaccination: cases (\%)

< 5: $54(1.9)$

6: $48(6.3)$

7: $95(14.7)$

8: $79(19.0)$

9: $50(32.0)$

10: $17(17.6)$

$>10: 13(23.1)$

Notified cases

2007

$39.3 / 100,000$

inhabitants

1994-2007 
Table 2 continued

Country, design, periodAge, $\mathrm{N}$

Germany [52]

Brandenburg, case-cohort

Aged $<18$ years

2002-2012

3,219 cases

Ireland [53]

Case surveillance (outbreak)

2010

All ages

67 possible cases

Ireland [54]

Hospital based, case surveillance

September 2003 to December 2009

All ages

1324 suspected cases

Luxembourg [55]

Active-surveillance, migrant cohort

May to September 2012

13-70 years

172 migrants arriving from 30 countries of

67 cases in 2010

\section{Laboratory method of diagnosis}

Notified cases

Culture, serology (test and cutoff not stated)

(n)

\section{PCR}

Culture

Anti-PT IgG (no cutoff stated) 
Table 2 continued

Country, design, periodAge, $\mathrm{N}$

The Netherlands $[58,59]$

Population-based, national surveillance

1996-2004 and 2005-2010

2001-2012

All ages

Notified cases

The Netherlands [56]

Case surveillance (outbreak convent)

1992

55-94 years

75 retired nuns and 24 staff members

\section{Laboratory method of diagnosis}

Notifications, various diagnostic methods

Overall: $32 / 100,000$

(1996-2004) to

$37 / 100,000$

(2005-2010)

Aged $\geq 10$ years:

$15 / 100,000$

(1996-2004) to

$33 / 100,000$

(2005-2010)

Overall: 63/100,000

(2001-2012)

Aged $>9$ years: $6.8 /$

100,000

(2005-2010) to

$59.1 / 100,000$

(2011-2012)

PCR, culture, threefold rise in $\geq$ threefold rise in sera antibody titre or anti-PT IgG $\geq 100 \mathrm{IU} / \mathrm{ml}$

Age: no. cases/total (\%)

55-64 years: $8 / 16(50)$

65-74 years: $13 / 21$

(62)

75-84 years: $16 / 27$

(59)

85-94 years: $8 / 11(73)$ 
Table 2 continued

Country, design, periodAge, $\mathbf{N}$

The Netherlands [60]

Population-based, national surveillance

January 1998-2001 (without preschool booster) and 2002- December 2005

(with preschool booster)

All ages

Notified cases

\section{Laboratory method of diagnosis}

Notifications, various diagnostic methods

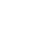


Table 2 continued

\section{Country, design, periodAge, $\mathrm{N}$}

The Netherlands [63]

Population-based, active surveillance

February 2006 and July 2007

$10-79$ years

7903 random samples

The Netherlands [62]

Population-based, active surveillance

2011-2014

10-18 years

239 random samples

UK, England [70]

Population-based, national surveillance

2010 to 2015

All ages

9163 reported cases

UK, England [68]

Population-based, national surveillance

January 2013 to December 2015

All ages

Notified cases

\section{Laboratory method of diagnosis}

PT $\mathrm{IgG} \geq 62.5 \mathrm{IU} / \mathrm{mL}$

$\mathrm{PT} \mathrm{IgG} \geq 50 \mathrm{IU} / \mathrm{ml}$

PCR

$\mathrm{PT} \mathrm{IgG} \geq 70 \mathrm{IU} / \mathrm{ml}$

PCR, culture

10 years: $7616(83$

Incidence/100,000

2012: 17.6

2013: 8.6

2014: 6.2

2015: 7.7 
Table 2 continued

\begin{tabular}{lll}
\hline Country, design, periodAge, N & Laboratory method of diagnosis & Key findings \\
\hline UK, England and Wales [67] & PT IgG $\geq 100 \mathrm{IU} / \mathrm{ml}$ & Incidence/100,000: \\
Population-based, national surveillance & & $1987: 211$ \\
1987 to 1998 & & $1988: 71$ \\
$<10$ years & $1989: 160$ \\
Notified cases & $1990: 204$ \\
& & $1991: 69$ \\
& & $1992: 29$ \\
& & $1993: 51$ \\
& & $1994: 48$ \\
UK, England and Wales [66] & $1995: 23$ \\
Population-based, national surveillance & $1996: 29$ \\
No82 to 2012 & PCR, culture & $1997: 36$ \\
Notified cases & $1998: 20$ \\
& & Age: no. cases $2002:$ \\
& $2012:$
\end{tabular}


Table 2 continued

Country, design, periodAge, $\mathrm{N}$

UK, England [65]

Population-based, national surveillance

2012 to 2013

All ages

Notified cases

\section{UK [71]}

Healthcare-based, case surveillance

October 2001 and March 2005

$6.5-12.5$ years

62 with cough $\geq 2$ weeks

UK [72]

Healthcare-based, case surveillance

1995

16-60 years

56 patients with cough
PT IgG $\geq 100 \mathrm{IU} / \mathrm{ml} \quad$ 20/56 (35.7\%)

\section{Laboratory method of diagnosis}

PCR, culture

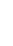

\section{Key findings}

Total cases (year)

304 (2010); 629

(2011); 5909 (2012);

3795 (2013)

Age; year, cases (\%)

$1-4$ years: 2010,7

(2.3); 2011, 10 (1.6);

2012, 58 (1.0); 2013 ,

$41(1.1)$

5-19 years: 2010,59

(19.4); 2011, 124

(19.7); 2012, 1128

(19.1); 2013, 669

(17.1)

$\geq 20$ years: 2010,186

(61.2); 2011, 349

(55.5); 2012, 4311

(73.0); 2013, 2984

(78.6)

PCR

$62(36.5 \%)$ 
Table 2 continued

\begin{tabular}{lll}
\hline Country, design, periodAge, $\mathbf{N}$ & Laboratory method of diagnosis & Key findings \\
\hline UK [73] & PT IgG and IgA: $\geq 2$ antibodies with levels $\geq 2 \quad 40(28 \%)$ \\
Healthcare-based, case surveillance & $\begin{array}{l}\text { SD or at least one antibody with a level } \geq 3 \mathrm{SD}, \\
\text { above the mean of the age matched controls }\end{array}$ \\
March 1996 to November 1997 & & \\
$5-78$ years (mean 31 years) & & \\
145 with cough $\geq 3$ weeks & & \\
\hline
\end{tabular}

$C I$ confidence interval, $P C R$ polymerase chain reaction, $P T$ pertussis toxin, $I g G$ immunoglobulin, $H C W$ healthcare worker, $S D$ standard deviation

cases among children aged 15-19 years (from 58 to 52 cases) and an increase among children aged 10-14 years (from 69 to 104 cases) [32].

Published studies identified for review provided epidemiological data in Sweden up to 2007 and these studies were used to inform the Public Health Agency of Sweden on vaccination policy [28-31]. In a study in Sweden that tracked the incidence of culture- or laboratoryconfirmed cases over a 10-year period (1997-2007), the incidence of pertussis was reduced among adults after the introduction of infant DTaP vaccination, particularly among those aged 25-35 years [29]. There were two further serosurveys studies in Sweden, one in 1997 when the new pertussis vaccination programme had been in place for 1 year $(n=3420)$ and the other was performed in 2007 to assess the effect of vaccination on anti-PT IgG antibody prevalence $(n=2379)$. In younger children, the proportion with anti-PT IgG $\geq 50$ and $\geq 100$ European units (EU)/ml was significantly higher in 1997 than in 2007 for both cutoffs. For all adults aged $\geq 20$ years, the difference in proportions with anti-PT $\operatorname{IgG} \geq 50$ $\mathrm{EU} / \mathrm{ml}$ was close to statistical significance comparing 1997 with 2007, yet this was not the case at anti-PT IgG $\geq 100 \mathrm{EU} / \mathrm{ml}$. In the 1997 samples of children, there was a significant downward trend in the rates of those above both cutoffs, and the rates of anti-PT IgG $\geq 50 \mathrm{EU} / \mathrm{ml}$ for three sampled age groups aged between 5 and 15 years ranged from $21 \%$ at age $5.0-5.5$ years to $7 \%$ at age $14.7-15.7$ years. In
2007, among samples of children, there was a significant continuous upward trend at both cutoff points, and the rates of anti-PT IgG $\geq 50$ $\mathrm{EU} / \mathrm{ml}$ for four sampled age groups between 4 and 18 years ranged from $4 \%$ at age $4-5$ years to $16 \%$ at $17-18$ years [31].

\section{Norway}

In Norway, the NIP includes DTaP at 3, 5, 12 months and 7 years, and an aP booster at 18 years [34]. One study in Norway showed that among 464 healthy military recruits in 2004, the rate of anti-PT IgG $>80 \mathrm{IU} / \mathrm{ml}$ was $8.4 \%$ [27].

\section{Western Europe}

An overview of epidemiology studies in Western European countries is shown in Table 2. Countries for which study data were available included Austria [35], Belgium [36-38], France [39-46], Germany [47-52], Ireland [53, 54], Luxembourg [55], The Netherlands [56-63], Switzerland [64] and the UK [65-73].

\section{Austria}

In Austria, the NIP includes three doses of aP from aged 3-12 months, minimum 6-month interval after second dose, a booster dose in children aged 8-9 years, and every 10 years in adults and every 5 years in adults aged $\geq 65$ years [34]. 
Table 3 Overview of epidemiology studies of pertussis in Central and Eastern Europe Western Europe

\begin{tabular}{|c|c|c|}
\hline Country & Design, period & Age, $n$, sample type \\
\hline Bulgaria $[77]$ & \multirow[t]{5}{*}{ PCR } & $<1$ year: 18 cases \\
\hline $\begin{array}{l}\text { Hospital-based, active- } \\
\text { surveillance }\end{array}$ & & $\begin{array}{l}1-3 \text { years: } 6 \text { cases } \\
10-14 \text { years: } 2 \text { cases }\end{array}$ \\
\hline 2009 to 2016 & & \\
\hline $\begin{array}{l}\text { Children and } \\
\text { adolescents }\end{array}$ & & \\
\hline 28 cases & & \\
\hline Bulgaria $[78]$ & \multirow[t]{4}{*}{ PCR } & $<1$ year: 12 \\
\hline $\begin{array}{l}\text { Population-based, } \\
\text { national surveillance }\end{array}$ & & $\begin{array}{l}\text { 1-4 years: } 9 \\
\text { 5-9 years: } 7\end{array}$ \\
\hline 2009 to 2015 & & $10-19$ years: 0 \\
\hline $\begin{array}{l}\text { All ages } \\
\text { Notified cases }\end{array}$ & & $\geq 20$ years: 1 \\
\hline Bulgaria [79] & \multirow[t]{5}{*}{ Pertussis antibody levels $>0.1 \mathrm{IU}$ 'fully protected' } & Age years $(\mathrm{n})$ \\
\hline $\begin{array}{l}\text { Population-based, active } \\
\text { surveillance }\end{array}$ & & $\begin{array}{l}7-15 \text { (609): } 30.7 \% \\
16-25 \text { (1977): } 16.55 \%\end{array}$ \\
\hline $2001-2008$ & & $26-35(1766): 38.75 \%$ \\
\hline$>7$ years & & $36-45$ (758): $21.65 \%$ \\
\hline 5887 samples & & $\begin{array}{l}46-55(581): 16.65 \% \\
>56(506): 0.6 \%\end{array}$ \\
\hline Estonia $[96]$ & \multirow{5}{*}{$\begin{array}{l}\text { PCR positive and single PT-IgG was }>100 \mathrm{IU} / \mathrm{ml} \\
\text { or } \\
\text { PT-IgG } 40-100 \mathrm{IU} / \mathrm{ml} \text { and PT-IgA }>12 \mathrm{IU} / \mathrm{ml}\end{array}$} & Total: 22 cases \\
\hline $\begin{array}{l}\text { Hospital based, case } \\
\text { surveillance }\end{array}$ & & $\begin{array}{l}\text { Age, } \% \text { cases } \\
<1 \text { year: } 5.6 \%\end{array}$ \\
\hline $\begin{array}{l}\text { April } 2012 \text { to } \\
\text { December } 2014\end{array}$ & & $\begin{array}{l}1-9 \text { years: } 5.6 \% \\
10-17 \text { years: } 6.3 \%\end{array}$ \\
\hline All ages & & $18-64$ years: $3.1 \%$ \\
\hline $\begin{array}{l}549 \text { with } \\
\text { cough } \geq 7 \text { days }\end{array}$ & & $\geq 65$ years: $0 \%$ \\
\hline
\end{tabular}


Table 3 continued

\begin{tabular}{|c|c|c|}
\hline Country & Design, period & Age, $n$, sample type \\
\hline Estonia $[165]$ & Culture or PT $\operatorname{IgA} / \operatorname{IgM}>12 \mathrm{IU} / \mathrm{ml}$ & 54 cases $(36 \%)$ \\
\hline \multirow{2}{*}{\multicolumn{2}{|c|}{$\begin{array}{l}\text { Case surveillance } \\
\text { (school outbreak) }\end{array}$}} & Age: no. cases \\
\hline & & 7 years: 1 \\
\hline \multicolumn{2}{|l|}{2003} & 8 years: 5 \\
\hline \multicolumn{2}{|l|}{$10-16$ years } & 9 years: 5 \\
\hline \multirow[t]{7}{*}{150 students } & & 10 years: 7 \\
\hline & & 11 years: 8 \\
\hline & & 12 years: 8 \\
\hline & & 13 years: 8 \\
\hline & & 14 years: 3 \\
\hline & & 15 years: 5 \\
\hline & & 16 years: 4 \\
\hline Estonia [82] & $\mathrm{PT} \operatorname{IgG} \geq 125 \mathrm{IU} / \mathrm{ml}$ & $2.0 \%$ \\
\hline $\begin{array}{l}\text { Population-based, active } \\
\text { surveillance }\end{array}$ & $\mathrm{PT} \operatorname{IgG} \geq 62.5$ to $<125 \mathrm{IU} / \mathrm{ml}$ & $5.6 \%$ \\
\hline \multicolumn{3}{|l|}{ April to August 2012} \\
\hline \multicolumn{3}{|l|}{$\geq 7$ years } \\
\hline \multicolumn{3}{|l|}{1053 random samples } \\
\hline Estonia $[83]$ & $\mathrm{PT} \operatorname{IgG} \geq 62.5$ to $<125 \mathrm{IU} / \mathrm{ml}$ & $2.7 \%$ \\
\hline $\begin{array}{l}\text { Population-based, active } \\
\text { surveillance }\end{array}$ & $\mathrm{PT} \operatorname{IgG} \geq 125 \mathrm{IU} / \mathrm{ml}$ & $0.6 \%$ \\
\hline \multicolumn{3}{|l|}{ January to February } \\
\hline \multicolumn{3}{|l|}{2013} \\
\hline \multicolumn{3}{|l|}{$20-99$ years } \\
\hline \multicolumn{3}{|l|}{3327 random samples } \\
\hline Czech Republic [81] & Serology assay & Age: incidence/100,000 \\
\hline Population-based, active & & 0 year: $15.6(2000) ; 4.4(2001)$ \\
\hline surveillance & & $1-4$ years: 9.1 (2000); $5.6(2001)$ \\
\hline $2000-2001$ & & $5-9$ years: $6.6(2000)$ and $4.7(2001)$ \\
\hline $0-64$ years & & $10-14$ years: $11.3(2000) ; 8.2(2001)$ \\
\hline 3194 random samples & & $\geq 20$ years: $0.1(2000) ; 1.2(2001)$ \\
\hline
\end{tabular}


Table 3 continued

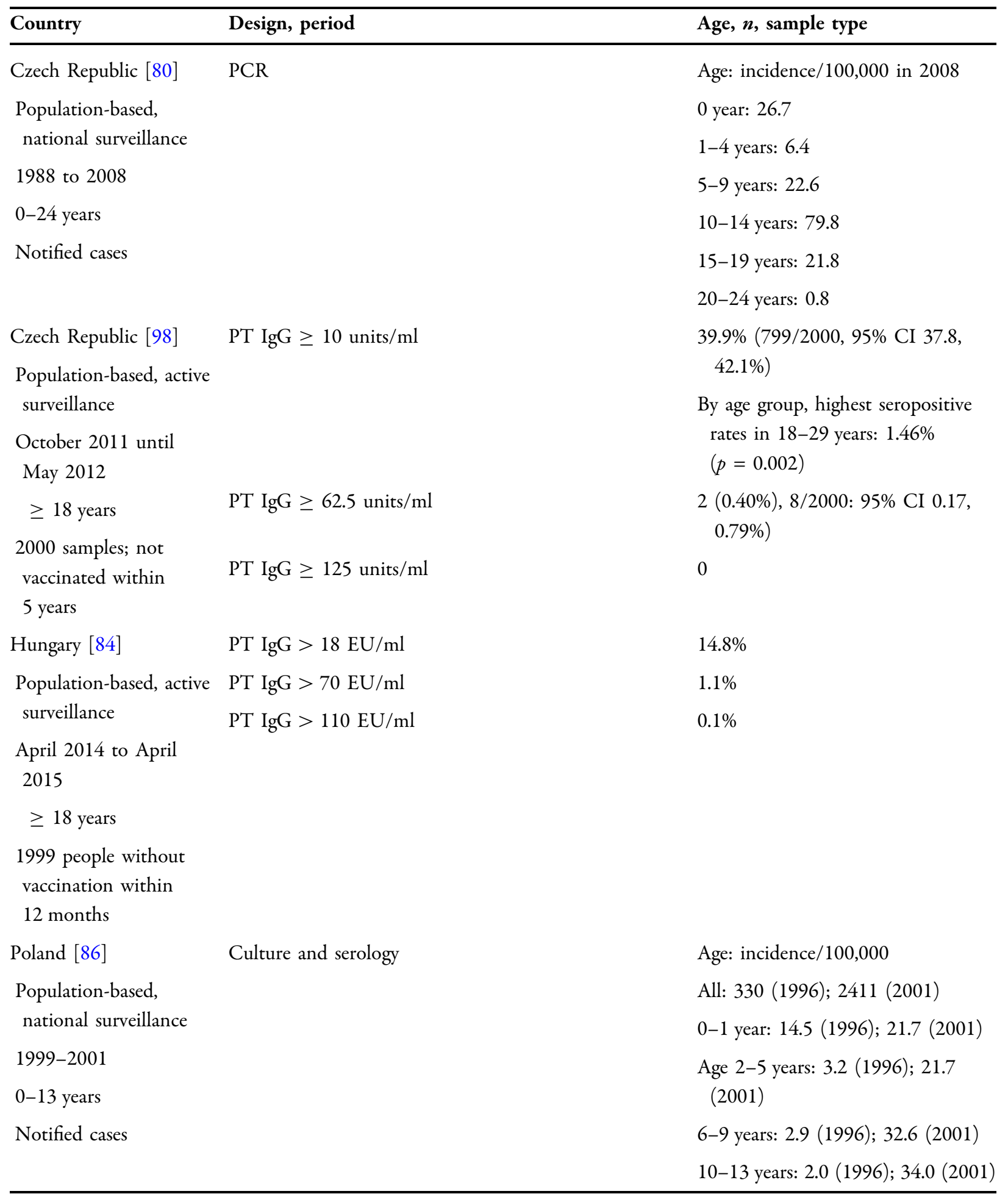


Table 3 continued

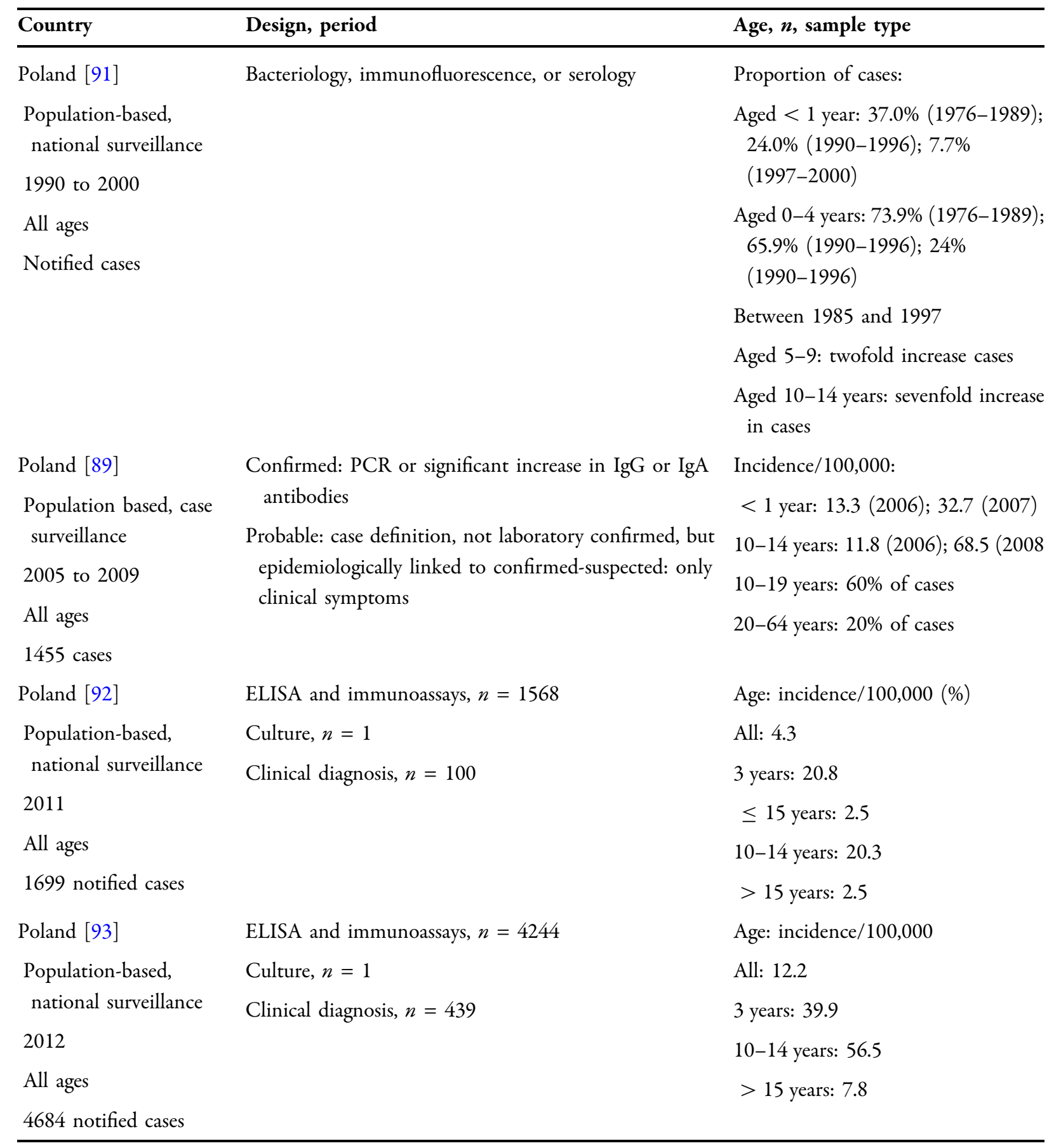


Table 3 continued

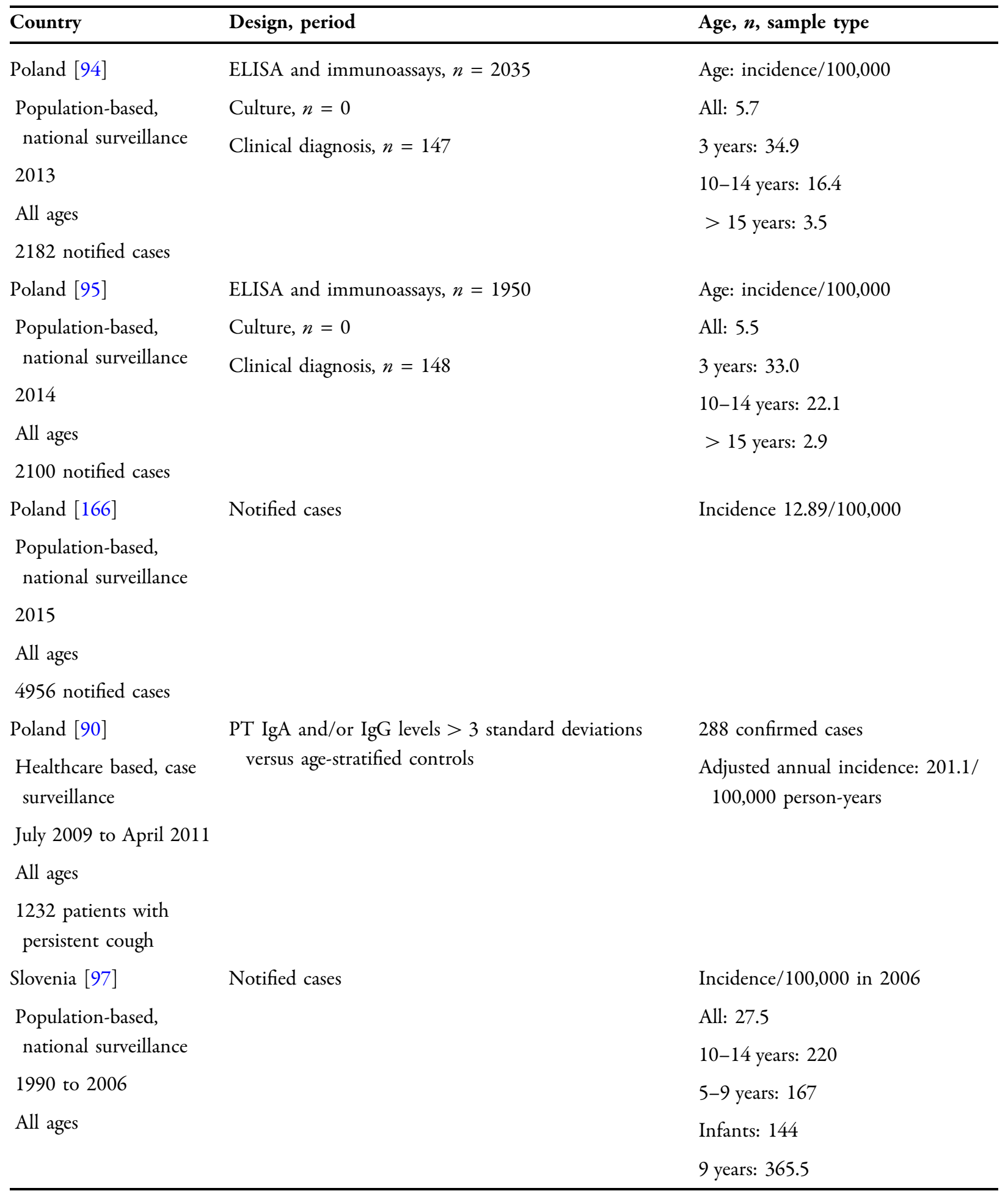


Table 3 continued

\begin{tabular}{|c|c|c|}
\hline Country & Design, period & Age, $n$, sample type \\
\hline Slovenia [87] & PT IgG 5.0-9.9 U/ml & $\mathrm{n} ; \%(95 \% \mathrm{CI})$ \\
\hline \multirow{2}{*}{$\begin{array}{l}\text { Population-based, active } \\
\text { surveillance }\end{array}$} & & $510 ; 14.9 \%(11.81-17.99)$ \\
\hline & PT IgG $10.0-50.9 \mathrm{U} / \mathrm{ml}$ & $2207 ; 64.6 \%(62.61-66.59 \%)$ \\
\hline 2000 & PT IgG 51.0-124.9 U/ml & $228 ; 6.7 \%,(3.5-9.9 \%)$ \\
\hline $0-60$ years & $\mathrm{PT} \mathrm{IgG}>125 \mathrm{U} / \mathrm{ml}$ & $80 ; 2.3 \%(0.9-5.5 \%)$ \\
\hline 3418 random samples & & \\
\hline
\end{tabular}

$C I$ confidence interval, $P T$ pertussis toxin, $\operatorname{Ig} G$ immunoglobulin

One study identified from Austria assessed serology among 184 suspected cases in children aged up to 16 years between 1995 and 1998. The results showed that the majority of cases were among un- or partly vaccinated infants, and the incidence of cases, confirmed by PCR and culture, of PT IgG or IgA seroconversion among paired sera was 71 cases/100,000 population overall. The incidence of pertussis among children with cough was estimated at 1841 cases/ 100,000 for those aged $6-10$ years and at 302 cases/100,000 population among children aged 11-16 years [35].

\section{Belgium}

In Belgium, the NIP includes DTaP at 2, 3, 4, 15 months and 5 years and aP booster at 14-16 years (added to the schedule in 2009), then every 10 years, and for pregnant women at 24 to 32 weeks gestation [34]. In a populationbased surveillance study in Flanders, Belgium, among notified cases of all ages (PCR, culture or serology), there were 208 cases in 2008 and 356 cases in 2012, representing a $71 \%$ increase, of which 181 cases were in those aged $>5$ years [36]

\section{France}

In France, the NIP was modified in 2013, from a recommended DTaP vaccination at $2,3,4$ and 16-18 months to 2,4 and 11 months. The infant series has been mandated since 2018 . The programme has also recommended aP vaccination at 6 years since 2013 and at 11-13 years since 1998 [34]. In 2006, a Tdap booster was introduced for individuals aged 25 years who had not received pertussis vaccine within the previous 5 years and for those aged 25-39 years who had not received Tdap booster. A booster dose every 20 years is currently recommend for adults in France as well as cocooning of unvaccinated infants [34].

In a healthcare-based surveillance study of adults presenting with persistent cough during a 7-month period in 1999, of 2017 patients, 200 had laboratory-confirmed pertussis including 1 culture-positive case, 36 PCR-positive, 40 with $\geq$ twofold change in anti-PT IgG and 60 with $\geq$ twofold change in anti-PT IgA [45]. The estimated annual incidence of pertussis in adults was 884 cases $/ 100,000$ population (95\% CI, 601-1199 cases/100,000 population) [45]. In a serosurvey of adults attending a French travel vaccination clinic between June and December $2005,7.6 \%$ overall and $13.4 \%$ of those aged 18-29 years had anti-PT IgG $\geq 125 \mathrm{IU} / \mathrm{ml}$ [46].

A study of outbreaks in France between 2002 and 2005 showed that of 595 notified pertussis cases, of which $<50 \%$ were confirmed by PCR, culture or serology, there were 197 and 331 cases in individuals aged $<15$ years and $>15$ years, respectively [40]. The most recent studies in France were population-based, case-surveillance analyses, reporting a crude incidence of PCR-confirmed pertussis of $145 / 100,000$ in 2008-2009 in adolescents and adults and of 103-256/100,000 in 2013-2014 in adults aged $>50$ years $[39,41,43]$. 
Table 4 Overview of epidemiology studies of pertussis in Southern Europe

\begin{tabular}{|c|c|c|}
\hline Country & Design, period & Age, $n$, sample type \\
\hline Cyprus [99] & \multirow{5}{*}{$\begin{array}{l}\text { Laboratory confirmed, PT IgA } \\
\quad \text { (no cutoff stated) }\end{array}$} & 24 cases \\
\hline Case surveillance (outbreak) & & 2 cases aged $<10$ years \\
\hline June to July 2003 & & 16 cases aged $10-20$ years \\
\hline All ages & & 6 cases aged $>20$ years \\
\hline \multicolumn{2}{|l|}{71 suspected cases } & \\
\hline Greece $[100]$ & \multirow[t]{8}{*}{ PCR } & 245 cases \\
\hline Hospital-based, case surveillance & & $85 \%$ of those aged $\geq 8$ years \\
\hline 1999-2008 & & $45 \%$ of those aged $<4$ years \\
\hline All ages & & 45 (78.9\%) household contacts \\
\hline 283 children hospitalised/ clinical diagnosis & & $23(69.7 \%)$ adults with chronic \\
\hline 57 household contacts of children with & & cough \\
\hline laboratory diagnosis & & Among children with a clinical \\
\hline 33 adults with chronic cough & & $\begin{array}{l}\text { diagnosis, } 35 \text { had a close contact } \\
\text { with pertussis }\end{array}$ \\
\hline Greece [101] & \multirow{11}{*}{$\begin{array}{l}\text { Positive anti-PT and anti-FHA } \\
\text { IgG }\end{array}$} & Age: no. cases/N (\%): \\
\hline Population-based, active surveillance & & 1-60 days: $13 / 32(40.6)$ \\
\hline January to October 2000 & & 2-12 months: $19 / 32(59.4)$ \\
\hline \multirow[t]{8}{*}{$1-80$ years: 439 random samples } & & $1-4$ years: $21 / 34(61.8)$ \\
\hline & & $5-10$ years: $36 / 58(35.3)$ \\
\hline & & $11-20$ years: $40 / 72(62.1)$ \\
\hline & & $21-30$ years: $42 / 74(55.6)$ \\
\hline & & $31-40$ years: $24 / 36(56.8)$ \\
\hline & & $41-50$ years: $49 / 59(66.7)$ \\
\hline & & $>50$ years: $49 / 59(83.1)$ \\
\hline & & Total: $256 / 431(59.4)$ \\
\hline Italy [110] & PCR & $30(15.8 \%)$ \\
\hline \multicolumn{3}{|l|}{ Case surveillance (school outbreak) } \\
\hline \multicolumn{3}{|l|}{ April 2009} \\
\hline Children: 71 suspected cases & & \\
\hline
\end{tabular}


Table 4 continued

\begin{tabular}{l} 
Country \\
\hline Italy [109] \\
Hospital-based, case surveillance \\
September 2013 to December 2014 \\
643 children admitted with lower respiratory \\
tract infections
\end{tabular}

Italy [107]

Population-based, national surveillance

1961 to 2013

All ages

Notified cases

Italy [102]

Population-based, active surveillance

March 1988 to November 1989

6-19 years

3875 random samples (unvaccinated)

\section{Design, period}

PCR

Notified cases

.

PT IgG $>3$ times higher than negative sera
Age, $n$, sample type
78 positive samples: $\mathrm{n}(\%)$
11 (1.7\%) for B pertussis
2 (0.3\%) for B parapertussis
$52(8.1 \%) \mathrm{M}$ pneumoniae
9 (1.4\%) C pneumoniae
5 (0.8\%) L pneumophila

Age: incidence/100,000

(1998-2004)

1-4 years: $10.5-81.8$

5-9 years: $12.1-116.4$

Age: incidence $/ 100,000$

(2003-2004)

1-4 years: $1.6-11.2$

10-14 years: $2.5-13.6$

$\geq 15$ years: $0.0-1.1$

Age: incidence/100,000 (\%)

$1-<2: 273.90(19.6)$

$2-<3: 127.93(36)$

$3-<4: 214.94(42.6)$

4- < 5: 200.39 (55.3)

$5-<6: 151.15(68.9)$

6-9: 59.16 (76)

10-13: 12.83 (83)

$14-<15: 4.46(86)$

15-17: $1.75(90)$

18-19: 1.53 (95)

Culture or antibody titres $>2$ SD Range/GM; $n$ higher than GMT of control group
PT IgA: 214-374/271; 203

PT IgG: 122-913/305; 449

Adults: 180 with chronic unexplained cough 
Table 4 continued

\begin{tabular}{ll}
\hline Country & Design, period \\
\hline Italy $[104]$ & PT and FHA IgG 2 EU/ml, PRN \\
Active-surveillance, military cohort & IgG $3 \mathrm{EU} / \mathrm{ml}$ and PT IgA 10 \\
1994 to 1995 & $\mathrm{EU} / \mathrm{ml}$ \\
$17-25$ years & \\
416 military recruits &
\end{tabular}

Age, $n$, sample type

Antigen: no. cases with titre $>$ minimum level detection/N (\%)

IgG PT: 298/416 (71.6)

IgG FHA: 412/416 (99.0)

IgG PRN: $337 / 416$ (81.0)

IgA PT: 66/416 (15.9)

Italy [105]

PT $\mathrm{IgG} \geq 100 \mathrm{IU} / \mathrm{ml}$

$40 \%$ of parents

Hospital-based, case surveillance

2017 (publication date)

168 parents of: 55 infants hospitalised for pertussis; 33 infants with respiratory infection; 57 healthy infants

Italy [108]

Clinical diagnosis

Healthcare-based, case surveillance

2002

Children aged $<15$ years

Italy [106]

Population-based, active surveillance

April 2012 to March 2013

Adults: 639 random samples
PT IgG 20-49 IU/ml

PT IgG 50-99 IU/ml

PT $\operatorname{IgG} \geq 100 \mathrm{IU} / \mathrm{ml}$
Aged 10-14 years, incidence: $366 / 100,000$

Age; no. cases/N (\%)

20-29 years; 54/239 (22.6)

30-39 years; 61/248 (24.6)

$\geq 60$ years; $59 / 152(38.8)$

Total: 175/639 (27.2)

Age; no. cases/N (\%)

20-29 years; $23 / 239$ (9.6)

$30-39$ years; $23 / 248(9.3)$

$\geq 60$ years; $12 / 152$ (7.9)

Total: 58/639 (9.1)

Age; no. cases/N (\%)

20-29 years; $17 / 239$ (7.1)

30-39 years; 8/248 (3.2)

$\geq 60$ years; $7 / 152$ (4.6)

Total: $32 / 639(5.0)$ 
Table 4 continued

\begin{tabular}{|c|c|c|}
\hline Country & Design, period & Age, $n$, sample type \\
\hline $\begin{array}{l}\text { Spain }[115] \\
\text { Population-based, national surveillance } \\
1982-2005 \\
\text { All ages } \\
39,580 \text { notified case }\end{array}$ & $\begin{array}{l}\text { Laboratory-confirmed or } \\
\text { epidemiological linked to a } \\
\text { confirmed case }\end{array}$ & Incidence: $8.4 / 100,000$ \\
\hline Spain/Catalonia [121] & PT IgG $>100 \mathrm{EU} / \mathrm{ml}$ & Age, no. cases; incidence $/ 100,000$ \\
\hline Population-based, active surveillance & & $15-24$ years: $36 ; 5.7$ \\
\hline 1996 & & $25-34$ years: $8 ; 0.8$ \\
\hline 887 school children & & $35-44$ years: $5 ; 0.5$ \\
\hline 1249 adults & & $\begin{array}{l}45-54 \text { years: } 5 ; 0.6 \\
55-64 \text { years: } 1 ; 0.1 \\
>64 \text { years: } 1 ; 0.1 \\
\text { Total: } 177 ; 0.1 \\
\text { Urban } \geq 10,000: 143 ; 0.98 \\
\text { Rural < 10,000:36; } 0.97\end{array}$ \\
\hline $\begin{array}{l}\text { Spain }[112] \\
\text { Case surveillance (school outbreak) }\end{array}$ & $\begin{array}{l}\text { PCR or serology or } \\
\text { epidemiologically-linked }\end{array}$ & $\begin{array}{l}\text { Birth cohort (age): attack rate } \% \\
2002 \text { ( } 17 \text { years): } 37\end{array}$ \\
\hline May 2015 & & 2001 (16 years): 12 \\
\hline $12-17$ years & & 2000 (15 years): 8 \\
\hline 395 students & & 1999 (14 years): 4 \\
\hline and 47 teachers & & $\begin{array}{l}1998 \text { (13 years): } 3 \\
1999 \text { ( } 14 \text { years): } 2\end{array}$ \\
\hline Spain $[124]$ & PT IgG $>11.0 \mathrm{VE}$ & Total: $51.7 \%$ \\
\hline Active surveillance HCW cohort & & Age $(\mathrm{N}) ; \%(95 \% \mathrm{CI})$ \\
\hline 2004 (publication date) & & $19-24$ years $(96) ; 51.0(37-65)$ \\
\hline$\geq 25$ years & & $25-34$ years $(190) ; 46.3(36-57)$ \\
\hline 487 hospital personnel & & $\begin{array}{l}35-44 \text { years }(100) ; 53.0(40-66) \\
\geq 45 \text { years }(101) ; 56.4(44-69)\end{array}$ \\
\hline
\end{tabular}


Table 4 continued

\begin{tabular}{|c|c|c|}
\hline Country & Design, period & Age, $n$, sample type \\
\hline Spain $[123]$ & \multirow[t]{5}{*}{ PT IgG (cutoff not stated) } & $\%(95 \% \mathrm{CI})$ \\
\hline Population-based, active surveillance & & Male $(\mathrm{n}=204) ; 72.5(66.4-78.7)$ \\
\hline 1996 & & Female $(\mathrm{n}=949) ; 69.7$ \\
\hline $19-39$ years & & $(66.7-72.6)$ \\
\hline \multicolumn{2}{|l|}{1153 samples from health personnel } & \\
\hline Spain $[125]$ & PT IgG $>36-44 \mathrm{IU} / \mathrm{ml}$ & $22(10.0 \%)$ \\
\hline Active surveillance, $\mathrm{HCW}$ cohort & PT IgG > 45-99 IU $/ \mathrm{ml}$ & $23(10.5 \%)$ \\
\hline June 2008 and December 2010 & PT IgG $>100 \mathrm{IU} / \mathrm{ml}$ & $10(4.5 \%)$ \\
\hline \multicolumn{3}{|l|}{ Adults: $220 \mathrm{HCWs}$} \\
\hline Spain $[126]$ & PT $\operatorname{IgG} \geq 0.3 \mathrm{OD}$ & $228(31.8 \%)$ \\
\hline $\begin{array}{l}\text { Hospital-based, HCW cohort } \\
22 \text { November } 2012 \text { to May } 2013\end{array}$ & $\begin{array}{l}\mathrm{PT} \mathrm{IgG} \geq 1.0 \mathrm{OD}(\geq 100 \mathrm{EU} / \\
\mathrm{ml})\end{array}$ & $24(3.3 \%)$ \\
\hline 731 adults & PT $\operatorname{IgG} \geq 1.5 \mathrm{OD}$ & $5(0.7 \%)$ \\
\hline Spain $[127]$ & \multirow{4}{*}{ PT $\operatorname{IgG} \geq 2.0 \mathrm{OD}$} & 5 cases $46.0 / 100,000$ \\
\hline Population-based, case surveillance & & $2-5$ years: 2 cases $76 / 100,000$ \\
\hline February 2001 to January 2002 & & $6-10$ years: 2 cases; 59/100,000 \\
\hline$\leq 15$ years & & $11-15$ years: 1 case; $28 / 100,000$ \\
\hline \multicolumn{3}{|l|}{61 children with cough $\geq 2$ weeks } \\
\hline Spain $[114]$ & \multirow[t]{7}{*}{ Notified cases } & Incidence rate ratio $(95 \% \mathrm{CI})$ for \\
\hline Population-based, national surveillance & & 2010-2012 versus 1998-2001 \\
\hline 2010 to 2012 & & Total: $4.34(4.13-4.55)$ \\
\hline \multirow[t]{4}{*}{ All ages } & & 30-39 years: $13.16(9.63-17.98)$ \\
\hline & & $40-49$ years: $21.47(13.64-33.81)$ \\
\hline & & $15-49$ years: $14.06(11.63-16.99)$ \\
\hline & & $\geq 50$ years: $16.91(11.40-25.09)$ \\
\hline Spain $[122]$ & \multirow{5}{*}{$\begin{array}{l}\text { Suspected/clinical diagnosis, } \\
\text { confirmed/laboratory diagnosis } \\
\text { (test not stated) }\end{array}$} & Incidence $/ 100,000$ \\
\hline Population-based, national surveillance & & Aged 5-9 years: 3.04 \\
\hline 1997 to 2010 & & Aged $10-14$ years: 3.59 \\
\hline All ages & & Aged $15-44$ years: 0.29 \\
\hline 3397 suspected/confirmed cases & & Aged $>45$ years: 0.1 \\
\hline
\end{tabular}

$P C R$ polymerase chain reaction, $P T$ pertussis toxin, $\operatorname{Ig} G$ immunoglobulin, $S D$ standard deviation 


\section{Ireland}

In Ireland, the NIP includes DTaP at 2, 4, 6 months and $4-5$ years and a Tdap booster at 12-13 years. Pertussis vaccination for pregnant women between 27 and 36 weeks' gestation was introduced in 2013 [34].

There were two studies from Ireland including a case-surveillance study of a school outbreak in 2010 and a hospital-based assessment of suspected cases from 2003 to 2009. In the school outbreak study, among possible cases including 67 children and adults, one case was confirmed by culture and six by serology [53]. The attack rate of confirmed/probable/possible cases was $77.3 / 1000$ population in children aged $0-4$ years and 75.8/1000 population in children aged 10-14 years. Four cases were hospitalised, including three neonates and one adult aged 60 years. There were 20 cases in those aged $>19$ years, at an attack rate of $7.6 / 1000$ population. In the hospital study of 1324 suspected cases, $76(5.7 \%)$ were culture positive and 145 (10.95\%) were PCR positive; for both culture and PCR, the majority of cases were aged $<6$ months [54]. In the group aged 7 months -11 years, the rates by PCR and culture were $5.4 \%$ and $2.6 \%$, respectively. In the group aged 12-15 years, there was one positive case each by PCR and culture, and there were no cases in the group aged $>15$ years [54].

\section{Germany}

In Germany, the NIP includes DTaP at 2, 3, 4 and 11-14 months and an aP booster dose at 5-7 years and for children aged 9-17 years. An aP booster is recommended for adults 10 years after the last aP dose [34]. Before the introduction of the current infant pertussis schedule in reunified Germany in 1991, the incidence of pertussis was lower in former East Germany than in former West Germany, which was associated with the different NIPs used during the 1970s and 1980s between the different states [51]. In reunified Germany in 1995, infant aP vaccine replaced infant $\mathrm{wP}$ vaccine, and an adolescent booster dose was introduced in 2000 [51].

In an analysis of pertussis epidemiology in five former East German States, in 2007, the incidence of pertussis was 39.3 cases/100,000 inhabitants, with an increase in the proportion of adult cases from 20\% in 1995 to $68 \%$ in 2007. From 2002, the age-specific peak incidence was in children aged 5-9 years and 10-14 years, reaching an incidence of $>300$ cases $/ 100,000$ inhabitants in two of the states [51]. In a further analysis of a cohort in Brandenburg comprising 3219 cases among children aged $<18$ years between 2002 and 2012, the incidence of pertussis was 80.4 cases $/ 100,000$ inhabitants. The peak incidences shifted from children aged 5-14 years in 2004-2006 to children aged 10-17 years in 2011-2012, and in 2012, the peak incidence was among adolescents aged 15-17 years [52]. The aim of the cohort study was to assess vaccine effectiveness (VE) over time following the change from infant wP vaccine to infant aP vaccine and the introduction of the adolescent booster dose. The study showed that aP vaccine was effective; however, the high incidence of pertussis among school children and adolescents was likely associated with waning vaccine immunity and low vaccine coverage of booster doses [52].

There were five further epidemiological studies in Germany, of which two reported pertussis epidemiology this century. The most recent epidemiology study was a case-surveillance study during a school outbreak in 2005, which showed that of 104 cases in primary and secondary schools (92 cases were children/adolescents), the attack rate (PCR, culture or serology, cutoff not stated) increased from $4.2 \%$ (95\% confidence intervals [CI] 0.5\%-14.2\%) among children aged 5-7 years to $23.8 \%$ (95\% CI 14.9\%-34.6\%) among children aged 9 years, decreasing to $18.9 \%$ (95\% CI $9.4 \%-32.0 \%)$ among children aged 10 years, 9.8\% (95\% CI $2.7 \%-23.0 \%$ ) among children aged $11-19$ years and $16.7 \%$ (95\% CI 8.6\%-27.9\%) among adults aged $\geq 20$ years. The overall attack rate was $15.0 \%(70 / 467)$ [50]. In a study of infected households in Germany between 1992 and 1994, 104 children (85\%) and 18 adults (15\%) were the source of pertussis. These households consisted of 265 adults (aged 19-83 years), of whom 84 (31\%) had laboratory-confirmed pertussis. Of the 84 laboratory-confirmed adult cases, $81 \%$ had respiratory symptoms for $\geq$ 21 days, and compared with children, adults 
had fewer episodes of prolonged cough, vomiting and whoop [74].

\section{The Netherlands}

In The Netherlands, the NIP includes DTaP at 2, 3,4 and 11 months, a booster at 4 years (introduced 2005) and TdaP for pregnant women from 22 weeks gestation [34].

National surveillance in The Netherlands shows that pertussis epidemics occur every 2 to 3 years. A serosurvey conducted between 2006 and 2007 of a randomly selected age-stratified sample of 7903 people estimated that about 9\% of the population aged $>9$ years had had pertussis infection in the past year (PT IgG $>62.5$ $\mathrm{EU} / \mathrm{ml})$. The percentage was highest in those aged $65-79$ years (12\%). The overall pertussis seroprevalence had more than doubled compared with a decade earlier. The authors suggest that the increased seroprevalence was consistent with the steady increase in reported clinical cases and hospitalised cases in adolescents and adults in the past decade [63]. An analysis of pertussis hospitalisation and notifications in The Netherlands showed that during 2002-2005, in children aged 1-4 years, the incidences of hospitalisations and notifications, respectively, were $48 \%$ and $44 \%$ lower than during 1998-2001. Similarly, in children aged 5-9 years, the incidence of hospitalisations and notifications decreased by $32 \%$ and $15 \%$, respectively, between the same periods. However, among cohorts aged 10-19, 20-59 and $>60$ years, the incidence of notifications increased $60 \%, 44 \%$ and $68 \%$, respectively [60].

\section{Luxembourg}

In a small study of migrants arriving in Luxembourg in $2012(n=410)$ the highest seroprevalence (no cutoff stated) was found in those aged 13-20 years $(43.8 \%)$ and the lowest in those aged $41-50$ years (37.5\%) [55].

\section{The UK}

In the UK, the NIP includes DTaP at 8, 12, 16 weeks and 3 years and aP vaccine for pregnant women from 16 weeks gestation (introduced 2012) [75]. In the UK, infant wP vaccine was used until 2004, when it was replaced with aP vaccine [76].

A UK study of the effectiveness of maternal vaccination against pertussis compared the shift in the percentage of PCR/culture-confirmed cases by age groups between 2008 and 2013, which peaked in October 2012 (1565 cases) and then fell across all age groups [65]. For the first 9 months of 2013 compared with the same period in 2012, the greatest proportionate fall in confirmed cases (328 cases in 2012 vs. 72 cases in $2013,-78 \%, 95 \% \mathrm{CI}-372$ to 83 ) occurred in infants aged $<3$ months, although the incidence remained highest in this age group. In non-infant age groups ( $>1$ year) in the same period, confirmed cases in 2013 fell proportionately less (between 29 and 41\%) from 2012 and increased relative to 2011 .

Although the numbers reported remained small, cases in adults aged $\geq 20$ years were roughly double those in 2012 and more than triple those in 2011 [65]. In a subsequent publication reporting pertussis cases between 2012 and 2015, incidence fell from a peak of 17.6/ 100,000 in 2012 to 8.6, 6.2 and 7.7/100,000 in 2013, 2014 and 2015, respectively [68]. The overall increase in incidence relative to pre-peak in 2012 was observed in all age groups $>6$ months with the combined 3-year comparator periods (2009-2011 vs. 2013-2015) increasing from 1.5 to $3.1 / 100,000$ in those aged 6-11 months (2.1 times higher); 0.7 to $2.2 /$ 100,000 in those aged $1-4$ years (3.1 times higher); 0.6 to $4.6 / 100,000$ in those aged 5-9 years (7.7 times higher); 2.6 to $13.6 / 100,000$ in those aged $10-14$ years (5.2 times higher); 1.1 to $7.4 / 100,000$ in those aged $\geq 15$ years (6.7 times higher). The greatest increase was observed in children aged 5-9 years [68].

In a serosurvey in the UK between 1996 and 1997, samples were taken from 356 patients who were diagnosed clinically with acute laryngitis/tracheitis or whooping cough (acute spasmodic cough of three weeks duration). Forty out of 145 who provided specimens for serological testing had evidence of recent infection with $B$ pertussis (increased anti-PT IgG levels versus controls). The prevalence among those aged 5-14 years was $45 \%$, and prevalence 
declined with increasing age until age $>65$ years, when it increased to $22 \%$ [73].

\section{Central and Eastern Europe}

An overview of epidemiology studies in Central and Eastern European countries is shown in Table 3. Data were reported from Bulgaria [77-79], Czech Republic [80, 81], Estonia [82, 83], Hungary [84], Poland [85] and Slovenia $[86,87]$.

\section{Poland}

The NIP in Poland mandates DTwP 2, 4, 6 and 16 months and an aP booster at 6 years and 14 years [88]. There were ten studies of pertussis epidemiology in Poland [86, 89-95], including several publications providing annual notified cases in 2005 and 2009 and between 2011 and 2015.

Among 1455 reported pertussis cases between 2005 and 2009, the incidences were highest in two groups: infants aged $<1$ year, from $13.3 / 100,000$ in 2006 to $32.7 / 100,000$ in 2007, and children aged 10-14 years, from 11.8/ 100,000 in 2006 to $68.5 / 100,000$ in 2008 . Adolescents aged 10-19 years accounted for $60 \%$ of cases and adults aged 20-64 years accounted for $20 \%$ of cases. Infants aged $<1$ year accounted for only $4 \%$ of cases [89].

Population-based, national surveillance showed that in most years between 2010 and 2015 infants and young children were the most affected groups, apart from 2012 when the incidence in older children aged 10-14 years was $56.5 / 100,000$ population and in those aged $>15$ years, was $7.8 / 100,000$, with these two age groups accounting for $77 \%$ of cases in 2012 compared with $67 \%$ in $2010,73 \%$ in 2011 , $66 \%$ in 2013 and $65.1 \%$ in 2014 [86, 89-95]. In 2011 , in adolescents aged 10-14 years and those aged $>15$ years, the age-adjusted incidences were $20.3 / 100,000$ and $2.5 / 100,000$, respectively. In 2011, half of the cases occurred in people aged $>15$ years, while one in three cases in children was in children aged 0-4 years and 5-9 years [92]. The same was observed in 2012 where the majority of cases were in children aged $10-14$ years and $>15$ years $(77 \%)$ [93] and in 2013 where the majority of cases occurred in adolescents aged $>15$ years (92\%) [94]. In 2014, adolescents were still the largest group (46\%) but were not the most cases [95].

\section{Estonia}

The NIP in Estonia includes DTaP at 3, 4, 6 months and 2 years, a booster at 6-7 years (introduced in 2008) and aP booster dose at 15-17 years (introduced in 2012) [96]. A wP vaccine was used in Estonia until 2008, when it was replaced by an aP vaccine [96].

There were four studies from Estonia, and the most recent was a hospital-based study between 2012 and 2014 including 549 patients with cough $\geq 7$ days. There were 22 cases of pertussis (PCR and anti-IgG $>100 \mathrm{IU} / \mathrm{ml}$ ), of which $5.6 \%$ were aged $1-9$ years, $6.3 \%$ aged 10-17 years, $3.1 \%$ aged $18-64$ years and none aged $\geq 65$ years [96]. Population-based active surveillance of 3327 adults showed that between January and February 2013, 2.7\% had anti-PT IgG $\geq 62.5$ to $<125 \mathrm{IU} / \mathrm{ml}$ and $0.6 \%$ had anti-PT IgG $\geq 125 \mathrm{IU} / \mathrm{ml}$ [83].

\section{Bulgaria}

In Bulgaria, the NIP mandates DTaP at 2, 3, 4 and 16 months (not earlier than 12 months after the 3rd dose) and an aP booster at 6 years and 12 years [34]. A wP vaccine was used in Bulgaria until 2008 when it was replaced with an aP vaccine [78].

Bulgaria had 29 pertussis cases notified between 2009 and 2014, of which 5 were PCR confirmed, and the incidence rate was highest in infants aged $<1$ year ( 12 cases), followed by children aged 0-9 years ( 9 cases) [78]. In a Bulgarian study of hospitalised children and adolescents, among 28 PCR-confirmed cases between 2009 and 2016, 64\% were aged $>1$ year and $21 \%$ aged $1-3$ years, whereas only two cases were aged $10-14$ years [77].

\section{Slovenia}

The NIP in Slovenia mandates DTaP at 3, 5 and 11-18 months and an aP booster at 8 years. An aP booster dose is recommended for people aged $>65$ years and for pregnant women between 28 and 36 weeks gestation [34]. A wP 
vaccine was used in Slovenia until 1999, when it was replaced with an aP vaccine [97].

In Slovenia, cyclic outbreaks of pertussis were reported in the 1990s, and between 2003 and 2006, the number of reported cases increased 6.5 times. Based on national surveillance data, after 2003, there was a shift in the age distribution of pertussis cases, and between 2003 and 2005, the rates in adolescents aged 10-14 years increased from 35 to $47 \%$ compared with $2 \%$ in 1991 [97]. In 2005, in Slovenia for the first time, the highest rates were observed in adolescents rather than infants, and in 2006 the incidence of pertussis was $27.5 / 100,000$ population overall and 220/100,000 population in adolescents aged 10-14 years [97]. Active surveillance of 3418 population-based samples in Slovenia in 2000 showed that the rate of antiPT IgG $>125 \mathrm{U} / \mathrm{ml}$ was $2.3 \%$ and anti-PT IgG 62.5 to $<125 \mathrm{U} / \mathrm{ml}$ was $6.7 \%$ [87].

\section{Czech Republic}

The NIP in the Czech Republic mandates DTaP at 3, 5, 11-13 months and an aP booster at 5-6 years and 10-11 years. An aP booster is recommended for those aged $>65$ years and for pregnant women between 28 and 36 weeks' gestation, but this is not state funded [34]. In the Czech Republic, infant wP vaccine was used until 2007, when it was replaced with an aP vaccine [98].

Notified cases in the Czech Republic were assessed from 1988 to 2008, and the highest age-specific incidence was observed in adolescents aged 10-14 years, at 79.8/100,000, and most $(93.1 \%)$ cases were notified in children/ adolescents aged 0-19 years. During this period, the peak incidence moved from the youngest and pre-school age groups towards school-aged and older school-aged children [80].

\section{Hungary}

In Hungary, the NIP mandates DTaP at 2, 3, 4 and 18 months and an aP booster at 6 years and 11-13 years [34].

There was one study from Hungary which assessed pertussis antibodies in 1999 people in 2014-2015. Overall, 14.8\% had anti-PT IgG > $18 \mathrm{EU} / \mathrm{ml}, 1.1 \%$ had anti-PT IgG $>70 \mathrm{EU} / \mathrm{ml}$ and $0.1 \%$ had a anti-PT IgG $>110 \mathrm{EU} / \mathrm{ml}$. Logistic regression showed a significant relationship between increased rates of seropositivity and age $\geq 60$ years (odds ratio [OR], 1.97; $95 \%$ CI $1.39-2.80 ; p=0.0002)$ or $18-29$ years (OR, 1.67; 95\% CI 1.13-2.46; $\mathrm{p}=0.0094)$ vs. 45-59 years [84].

\section{Southern Europe}

An overview of epidemiology studies from Southern European countries is shown in Table 4. This included studies from Cyprus [99], Greece [100, 101], Italy [102-110], Portugal [85] and Spain [111-127].

\section{Cyprus}

Since 1996, the NIP in Cyprus has included $\mathrm{DTaP}$ at 2, 4, 6 and 18 months and at age 4-6 years [99]. In November 2002, pertussis was included in the active surveillance scheme, the Greece \& Cyprus Paediatric Surveillance Unit (GCPSU), and the only study from Cyprus identified for the review was a case surveillance study of an outbreak in 2003, including 24 cases with anti-PT IgA antibodies; the incidence was highest in young children $(n=22)$, and the majority of cases were in adolescents $(n=16)$ and adults $(n=6)$. The authors concluded that this confirms the shift in age of pertussis from children to adolescence and adults and that the main factors were waning immunity or incomplete immunisation [99].

\section{Greece}

The NIP in Greece includes DTaP 2, 4, 6 and 15-18 months and aP boosters at 4-6 years and 11-12 years and a booster dose in adulthood [34].

In Greece in 2000, among 431 serum samples from healthy subjects aged 1 day to 80 years, IgG antibodies to PT and filamentous haemagglutinin (FHA) were significantly elevated with age (analysis of variance (ANOVA), $p<0.001$ ). In addition, a significant increase in antibody levels was detected in adults aged $>50$ years compared with children aged 5-10 years (posthoc Scheffé analysis, $p=0.007$ ). These data suggest that pertussis occurs frequently in Greek 
adults and that sometimes a fifth booster vaccine dose is not given after the second year of life [101]. In another study in Greece in 2009, based on 373 adults aged 17-65 years, there were three groups: 283 children who were hospitalised with the clinical diagnosis of pertussis, 57 household contacts of 57 children with PCRconfirmed pertussis and 33 adults who suffered from chronic cough. Increased prevalence of pertussis was observed with increasing age [100].

\section{Italy}

The NIP in Italy involves legally mandated DTaP at 3, 5 and 11 months and an aP booster at 6 years and $12-18$ years since 2017 . An aP vaccine is recommended for adults, to be given 10 years after the final DTaP vaccination and for pregnant women in the third trimester [34].

A study using the Italian surveillance system tracked the incidence of notified diseases in 371,670 children aged $<15$ years in 2002 . The highest age-specific incidence rate was observed in children aged 1-4 years for varicella, rubella and measles, in children aged 5-9 years for mumps and in children aged 10-14 years for pertussis $(366 / 100,000)$ [108]. In a study in Italy conducted between 2013 and 2015, among 168 parents of children with pertussis, $40 \%$ were found to have anti-PT IgG $\geq 100 \mathrm{IU} / \mathrm{ml}$. Based on serology, the percentage of pertussis cases that had at least one parent as the source of infection was $49.1 \%$, and when cough symptoms were taken into account, the percentage of parents who could be considered as transmitters of the infection to their infants was $56.4 \%$ [105]. In another study of pertussis seroprevalence in Italy, using sera $(n=639)$ collected between 2012 and 2013 from adults aged 20-29 years and 30-39 years (reproductive age), and $\geq 60$ years, the proportion of people with anti-PT IgG > $100 \mathrm{IU} / \mathrm{ml}$ increased significantly from 9.3\% (95\% CI 7.5-11.1\%; 96/1037) in 1996-1997 to $14.1 \%$ (95\% CI $11.4-16.8 \%$; 90/639) in 2012-2013. By age, between 2012 and 2013, the rate of anti-PT IgG > $100 \mathrm{IU} / \mathrm{ml}$ was $7.1 \%$ for $20-29$ years, $3.2 \%$ for $30-39$ years and $4.6 \%$ for $\geq 60$ years [106]. A pertussis seroprevalence study of unvaccinated Italian children and adolescents $(n=3875)$ between 1998 and 1999 reported the overall prevalence of anti-PT IgG antibodies was $80.8 \%$ (measured absorbance $>3$ times greater than that of negative sera). Prevalence increased with age from $33.5 \%$ in those aged $1-3$ years to $95 \%$ in those aged 17-19 years [102].

\section{Spain}

In Spain the NIP includes DTaP at 2, 4 and 11 months and an aP booster at 6 years and 12-18 years. An aP booster is recommended for pregnant women from 27 weeks' gestation [34]. A wP vaccine was used up to 2005 when it was replaced with an aP vaccine.

Based on notified cases in Spain, compared with 1998-2001, in 2010-2012, the incidence rate increased notably in all age groups, with incidence rate ratios ranging from 2.5 (95\% CI $2.3-2.8)$ in children aged 5-9 years to 36.0 (95\% CI 19.4-66.8) in adults aged 20-29 years [114]. In Spain, between 1997 and 2010, there were 3397 notified cases of pertussis, with an incidence of 54.2/100,000 in infants aged $<1$ year, $3.59 / 100,000$ in adolescents aged 10-14 years and $0.1 / 100,000$ in adults aged $>45$ years [122]. The results are consistent with Spain's vaccination history and suggest a progressive increase in susceptible individuals due to waning immunity after years of low incidence. Pertussis has been reported to be circulating in healthcare workers (HCWs) in Spain, as reported by a study of 220 HCWs between 2008 and 2010, among which $10.5 \%$ has anti-PT IgG $>45-99$ $\mathrm{IU} / \mathrm{ml}$ and $4.5 \%$ had PT IgG $>100 \mathrm{IU} / \mathrm{ml}[125]$.

In a Spanish study of sera samples from 1153 'young adults' (aged 19-39 years), collected between 2007 and 2010, those aged 30-34 years (about $47 \%$ ) had the lowest seroprevalence for $B$ pertussis (PT IgG cutoff not stated) followed by an increase in those aged 35-39 years (60\%). The 25-29-year-old group had the highest seroprevalence (about 86\%) [123].

\section{MORTALITY}

There were 19 studies of pertussis deaths in Europe, including Germany [51, 128], Greece [129], Ireland [130], Italy [107, 131], The Netherlands [132-134], Poland [91], Portugal 
[135], Slovenia [97], Spain [136], UK [137-139], Ukraine [140] and pan-Europe [141, 142].

\section{Mortality Rates}

In a study of 79,217 pertussis cases reported to national surveillance systems in 16 European Union (EU) member states between 1989 and 2002, 11 countries collected information on death [141]. Overall, there were 32 deaths recorded, of which 1 was a child aged 5-9 years, 1 was aged $>14$ years and 30 were infants aged $<1$ year. The mortality rate for infants aged $<1$ year was $6.3 / 1000$ births. Most deaths $(n=26)$ were reported in France, and there were no fatal cases reported in Greece, Iceland, Malta and Switzerland [141]. In a similar study of deaths in the period 1998-2002, in which 16 European countries were included in a common database with data from pertussis cases gathered from routine national surveillance, the combined all-age mortality rate was $0.7 / 1000$ population [142].

In the UK, among 50 deaths between 1980 and 1990, the age range was 30 days to 58 years, and infants aged $<1$ year accounted for $74 \%$. The pertussis-related mortality rates were $1 / 21,000$ in children aged 5-14 years and $1 / 8250$ in those aged $>16$ years [138].

In Italy, between 1925 and 1994, in an era classified as 'pre-vaccination', the all-age mortality rate for pertussis was 2.4/100,000 population, which fell to zero in the 'postvaccination era' [131]. In The Netherlands, between 1976 and 1988, there were seven deaths from pertussis, six of which were in children aged $<1$ year [132]. In a study of an outbreak at a convent in The Netherlands in 1992, pertussis was diagnosed in 45/75 (60\%) retired nuns, of whom 4 died, including 3 who were aged $>75$ years [133]. Based upon 995,857 notified cases between 1976 and 2000 in Poland, the number of deaths fell from about 1000 in the 1950 s to single cases in the 1980s, with the last death from pertussis reported in 1991, although the ages of the fatal cases are not reported [91].

There were 9 pertussis-related deaths notified between 1970 and 2007 in the former East
Germany, 4 of which occurred in elderly adults in 2002, and in the former West Germany during the same period, there were 231 deaths, with mortality gradually decreasing. The last three deaths were reported in an infant in 2001, in an elderly woman in 2005 and in a teenager in 2007 [51]. A small-scale German study of 216 cases of pertussis reported 5 deaths between 1993 and 1996, of which 3 were previously healthy children. Two of the deaths were in children aged $0-6$ years $(n=73)$ and one in an adolescent aged $>9$ years $(n=11)$ [128].

\section{Case Fatality Rates}

Six studies provided case fatality rates in European countries, the most recent of which was a study in Portugal between 2000 and 2015, which showed that among 2281 hospitalised patients with pertussis (aged from birth to 65 years), the overall case fatality rate was $0.7 \%$ [135]. The case fatality rate was $11.5 \%$ in adults aged 18-64 years and $17.4 \%$ in adults aged $>65$ years [135]. In another study of patients hospitalised with pertussis in Spain, among 2216 cases recorded between 1995 and 1999, 14 were fatal. Most deaths (71\%) were among children aged $<1$ year, with two fatal cases in adults [136]. The case fatality rate was higher in people aged $>50$ years $(28.6 \%)$ compared with those aged $1-5$ years $(1.4 \%)$ and 1 year $(0.5 \%)$ [136].

Based on notifications in the UK, there were 5, 1, 1 and 3 pertussis-related deaths in 2008, 2009,2010 and 2011, at a case fatality rate of $3.4 \%, 1.1 \%, 2.3 \%$ and $2.5 \%$, respectively. In the epidemic year 2012, and in 2013, there were ten and two deaths at a case fatality rate of $3.0 \%$ and $2.8 \%$, respectively [65].

A study in the Ukraine, using a combination of notification data and the literature (from pre2000), showed that the overall case fatality rate was $0.163 \%$ between 1965 and 1991, rising to $0.183 \%$ between 1992 and 2005 and then declining to $0.106 \%$ between 2006 and 2015 [140]. In Italy, using national notification data between 1961 and 1994, the case fatality rate was $0-1 \%$ [107], and in Ireland between 1980 and 1984, the overall pertussis-related case 
fatality rate was $0.08 \%$, of which $83 \%$ were aged $<1$ year [130].

\section{DISCUSSION}

The most recent European Centre for Disease Prevention and Control (ECDC) estimates of pertussis incidence, based on notifications from 29 European countries, show that the most affected age group is infants and that the population aged $\geq 15$ years accounts for about $60 \%$ of cases [4]. Although the health status of populations is comparable across Europe, there is wide variation in the incidence of pertussis between countries. For example, in the ECDC report of annual notifications in 2017, Norway had the highest notification rate at 46.1/ 100,000, followed by The Netherlands (26.4), Germany (20.4) and Denmark (18.7), whereas in Greece, Romania and Hungary, the rate was $<1 / 100,000$ [4]. Robust surveillance systems for notifiable diseases are in place in all European countries, and most European countries report pertussis according to an EU case definition [143]. However, national surveillance systems vary from country to country, including diagnostic techniques and reporting regulations. For example, pertussis reporting was not mandatory in Germany until after 2013, and in France, the hospital-based sentinel surveillance system only includes infants aged $<6$ months [143]. In addition, although infant DTP vaccination coverage is high in most European countries, coverage varies, for example, in a study of 16 European countries, the coverage of infant DTP vaccination ranged from $89 \%$ in Romania to $98 \%$ in Finland and Sweden [144]. Moreover, in some countries infant DTP coverage has historically been lower than ideal (i.e. $<95 \%$ ), leading to vaccination becoming a legal requirement. In France, for example, coverage with hexavalent (DTaP-HBV-IPV-Hib) vaccine in children aged $<1$ year increased from $93 \%$ in 2017 , to $98 \%$ in 2018 , after vaccination was mandated [145]. Pertussis vaccination coverage among older children and adult groups is not well documented, and the NIP recommendations for these populations vary considerably between countries [145].
In 2006, the Global Pertussis Initiative (GPI), the Consensus on Pertussis Booster Vaccine in Europe and the US Advisory Committee on Immunization Practices recommended that pertussis vaccination should be expanded to include Tdap booster dose for adolescents and adults $[9,146,147]$. In the US, the introduction Tdap for adolescents in 2005 resulted in a large decrease in pertussis cases among adolescents aged 11-18 years, and in Australia, after vaccinating high school children in 2008-2009, there was a decrease in pertussis cases in adolescents [148, 149]. However, although Tdap vaccines are effective against pertussis in adolescents, three studies in the US showed that protection may be moderate and wane rapidly during 3 years after vaccination [150-152]. However, these studies assessed relative effectiveness, i.e. versus a vaccinated population, rather than absolute effectiveness, i.e. versus a vaccination-naïve population. A meta-analysis of these studies showed that the absolute vaccine effectiveness after boosting was 85\%, declining by $11.7 \%$ per year, suggesting that booster responses in adolescents were better than previously reported [153]. Several European countries now recommend Tdap for adolescents as a booster or as a catch-up dose, yet there are limited data from Europe on the effect of vaccinating adolescents [34]. France introduced Tdap for adolescents in 1998 and a study published in French reported that among pertussis cases in infants aged $<6$ months, the mean age of the contact person/source of infection increased from 19.6 years in 1996 to 31.9 years in 2007 [154]. In Sweden, 10 years after introducing a pre-school booster and a school-leaving booster at age 14-16 years, there was an increase in children with anti-PT IgG > $100 \mathrm{EU} / \mathrm{ml}$, yet in a cross section of adults over the same period, there was a decrease in the proportion with anti-PT IgG levels indicative of natural infection and a lower frequency of pertussis cases. The authors suggested that universal vaccination of children and adolescents in Sweden may have reduced natural exposure and herd immunity in adults [31].

Vaccination of adults is currently recommended in some European countries with the aim of reducing pertussis rates in older people 
who may serve as a reservoir for infection, although most countries do not include aP boosters for adults in the NIP [34]. National surveillance generally shows that pertussis is circulating in adolescents and adults in Europe. National surveillance in Denmark showed that in 2013 the incidence/100,000 of pertussis in people aged $30-39$ years was 7 , aged $40-49$ years was 9 and aged $\geq 50$ years was 3 compared with 110 in those aged $<1$ year [19]. In The Netherlands, between 2002 and 2005, the incidence/ 100,000 of pertussis in people aged $20-59$ years was 15.7 , and among those aged $\geq 60$ years was 11.7, compared with 132.3 in infants aged $<5$ months [60]. There are limited data on the effect of vaccinating adults; however, after the introduction of Tdap for adults aged 25-39 years in Paris, the incidence of pertussis in adults decreased from $884 / 100,000$ in $1999-2000$ to $145 / 100,000$ in 2008-2009 [155].

Vaccination during pregnancy is a primary prevention strategy to reduce the risk of pertussis infection in unvaccinated and partly vaccinated infants $[9,156]$. Pregnant women should be targeted because as well as reducing the risk of mother-to-infant infection, maternal Tdap vaccination is reported to induce high levels of transplacental antibodies that can protect the newborn [157]. Isolating vulnerable infants from contacts that could transmit infection (cocooning) is also a way to reduce the risk of transmission, although the effectiveness of the strategy is associated with the proportion of contacts that are vaccinated, i.e. parents and siblings [158, 159]. Therefore, the GPI strongly recommends the use of aP vaccine in pregnant women and also encourages booster doses in adolescents [159]. Several European countries currently recommend aP vaccine for pregnant women on the NIP, including Belgium, Czech Republic, Denmark, Ireland, Italy, The Netherlands, Slovenia, Spain and the UK [160].

All European countries have included infant DTP vaccination in the NIP for $>30$ years, and apart from Poland, all countries have replaced infant wP vaccine with infant aP vaccine. Acellular pertussis vaccines contain inactivated pertussis toxin (PT) and may contain one or more other bacterial components such as filamentous haemagglutinin (FHA), pertactin (Pn) and fimbriae (FIM) types 2 and 3. It is still unclear how other antigens than PT contribute to the protective effect of vaccines. Clinical and real-world studies show that all licensed pertussis vaccines are highly protective against pertussis and differences in protection among pertussis vaccines based on antigen number have not been confirmed [161]. A pre-school/ early school booster dose was introduced in most European countries circa 2003-2010, and currently all countries apart from Malta include a pre-school/early school booster dose [34]. Following guidance from the Consensus on Pertussis Booster Vaccination in Europe (COPE) group, in 2009, several countries introduced booster doses for adolescents. However, European countries that currently do not include an adolescent booster dose in the NIP include Denmark, The Netherlands, the UK, Romania, Spain and Portugal [34]. Currently, at least one booster dose of aP vaccine for adults is included in the NIP in Austria, Belgium, Liechtenstein, Germany, Iceland (individuals at risk) and Luxemburg [34].

Most of the studies identified that reported pertussis-related deaths in Europe did not include the epidemic outbreak in 2012. Based on notifications in Europe in 1998-2002, the overall pertussis-related mortality rate was $0.7 /$ 1000, and in 1989-2002, there were 30 deaths in infants aged $<1$ year, 1 death in a schoolaged child and 1 death in an adolescent [141]. Although the mortality rates in adults are extremely low, the reported case fatality rates for adults hospitalised for pertussis are relatively high. In a study in Portugal in 2000-2015, among adults aged 18-64 years hospitalised with pertussis, the case fatality rate was $11.5 \%$, increasing to $17.4 \%$ in those aged $>65$ years [135]. In a similar study in Spain in 1995, the case fatality rate was $28.6 \%$ in adults aged $>50$ years compared with only $1.4 \%$ and $0.5 \%$ in children aged $1-5$ years and 1 year, respectively [135]. Indeed, although pertussis disease is often mild in adults, data from Australia suggest that elderly people, particularly those with respiratory co-morbid conditions, are at a greater risk of pertussis-related hospitalisation and death than younger adults [162]. Interestingly, during an outbreak in a convent 
in The Netherlands in 1992 in which four nuns died, the incidence of pertussis increased with the time that the nuns had spent in isolation, but did not increase with age. Pertussis was confirmed in $2 / 24(8 \%)$ staff members and $45 / 75$ (60\%) nuns (unvaccinated), and most of the nuns had been retired and isolated in the convent for between 35 and 70 years, but had had a career outside the convent. There were nine nuns with a career entirely inside the convent, and all of them were positive for pertussis [56].

The real incidence of pertussis in Europe is likely to be much higher than that captured by surveillance systems; in particular, pertussis in adolescents and adults is likely to be underreported [9, 163]. Pertussis is known to be underdiagnosed in adults partly because the public and HCWs often regard pertussis as a childhood disease so that it is not considered, and also because pertussis is difficult to discern from other acute cough syndromes in adults $[11,164]$. Indeed, as well as increasing pertussis vaccination coverage in adolescents, adults and pregnant women in European countries, mitigation strategies should include improved diagnosis and treatment in lower risk populations.

The main limitation of this review is that it provides a narrative analysis of studies that differed widely in terms of pertussis surveillance and notification, case definitions and diagnostic methods as well as a lack of global consensus on anti-PT IgG antibody cutoffs. In addition, the review does not include non-English language publications, which might have excluded some studies that would have provided relevant data. However, the strength of the review was the use of the well-established technique of a systematic review to provide a comprehensive overview of pertussis in older children and adults in Europe.

\section{CONCLUSIONS}

Whereas infants and young children are routinely vaccinated against pertussis in European countries, few countries provide booster doses for adolescents and adults, suggesting that vaccine coverage among these groups across Europe is relatively low. Numerous studies show that pertussis is circulating among adults in Europe, yet active surveillance suggests that national surveillance likely underestimates the incidence of pertussis among older groups. As well as weaknesses in surveillance among older populations, low awareness among the public and among HCWs means that pertussis is likely underdiagnosed in European countries. Improved awareness and reporting systems are needed to help define the true burden of pertussis in older populations and their role in disease transmission.

\section{ACKNOWLEDGEMENTS}

Funding. Sponsorship for this study and the rapid service fees for the journal were funded by Sanofi Pasteur, France.

Editorial Assistance. The authors acknowledge Annick Moon of inScience Communications, Springer Healthcare Ltd, Chester, UK, for editorial assistance with the preparation of this manuscript. This assistance was funded by Sanofi Pasteur. The authors also thank Burnedette Rose-Hill for editorial assistance and manuscript coordination on behalf of Sanofi Pasteur.

Authorship. All named authors meet the International Committee of Medical Journal Editors (ICMJE) criteria for authorship for this article, take responsibility for the integrity of the work as a whole, and have given their approval for this version to be published.

Authorship contributions. Denis Macina: Conceptualization, methodology, investigation, Writing - review and editing. Keith Evans: Methodology, investigation, Writing-review and editing.

Disclosures. Denis Macina is an employee of Sanofi Pasteur and may hold shares and/or stock options in the company. Keith Evans was provided with funding by Sanofi Pasteur to conduct 
the literature review in collaboration with Denis Macina.

Compliance with ethics guidelines. This article is based on previously conducted studies and does not contain any studies with human participants or animals performed by any of the authors.

Data availability. Data sharing is not applicable to this article as no datasets were generated or analysed during the current study.

Open Access. This article is licensed under a Creative Commons Attribution-NonCommercial 4.0 International License, which permits any non-commercial use, sharing, adaptation, distribution and reproduction in any medium or format, as long as you give appropriate credit to the original author(s) and the source, provide a link to the Creative Commons licence, and indicate if changes were made. The images or other third party material in this article are included in the article's Creative Commons licence, unless indicated otherwise in a credit line to the material. If material is not included in the article's Creative Commons licence and your intended use is not permitted by statutory regulation or exceeds the permitted use, you will need to obtain permission directly from the copyright holder. To view a copy of this licence, visit http://creativecommons.org/licenses/bync/4.0/.

\section{REFERENCES}

1. World Health Organization: Global Health Observatory data. https://www.who.int/gho/ immunization/en/. Accessed Au 2020.

2. Domenech de Cellès M, Magpantay FM, King AA, Rohani P. The pertussis enigma: reconciling epidemiology, immunology and evolution. Proc Biol Sci. 1822;2016:283.

3. Amirthalingam G, Gupta S, Campbell H: Pertussis immunisation and control in England and Wales, 1957 to 2012: a historical review. Euro surveillance : bulletin Europeen sur les maladies transmissibles = European communicable disease bulletin 2013, 18(38).
4. European Centers for Disease Prevention and Control.: Pertussis. Annual Epidemiological Report for 2017. https://www.ecdc.europa.eu/en/publicationsdata/pertussis-annual-epidemiological-report-2017. Accessed Aug 2020.

5. Kamiya H, Otsuka N, Ando Y, Odaira F, Yoshino S, Kawano K, Takahashi H, Nishida T, Hidaka Y, Toyoizumi-Ajisaka $\mathrm{H}$, et al. Transmission of Bordetella holmesii during pertussis outbreak. Jpn Emerg Infect Dis. 2012;18(7):1166-9.

6. Smith T, Rotondo J, Desai S, Deehan H: Pertussis Surveillance in Canada: Trends to 2012. Canada communicable disease report $=$ Releve des maladies transmissibles au Canada 2014, 40(3):21-30.

7. European Centers for Disease Prevention and Control.: Pertussis. https://www.ecdc.europa.eu/sites/ portal/files/documents/Pertussis\%20AER.pdf. Accessed July 2021. 2014.

8. Cherry JD. The 112-year odyssey of pertussis and pertussis vaccines-mistakes made and implications for the future. J Pediatric Infect Dis Soc. 2019;8(4): $334-41$.

9. Esposito S, Principi N. Immunization against pertussis in adolescents and adults. Clin Microbiol Infect. 2016;22(Suppl 5):S89-s95.

10. World Health Organization.: Pertussis vaccines: WHO position paper, August 2015-Recommendations. Vaccine 2016, 34(12):1423-1425.

11. Kilgore PE, Salim AM, Zervos MJ, Schmitt HJ. Pertussis: microbiology, disease, treatment, and prevention. Clin Microbiol Rev. 2016;29(3):449-86.

12. Barkoff AM, Gröndahl-Yli-Hannuksela K, He Q: Seroprevalence studies of pertussis: what have we learned from different immunized populations. Pathog Dis 2015, 73(7).

13. Tondella ML, Carlone GM, Messonnier N, Quinn CP, Meade BD, Burns DL, Cherry JD, Guiso N, Hewlett EL, Edwards KM, et al. International Bordetella pertussis assay standardization and harmonization meeting report. Centers for Disease Control and Prevention, Atlanta, Georgia, United States, 19-20 July 2007. Vaccine. 2009;27(6): 803-14.

14. Guiso N, Berbers G, Fry NK, He Q, Riffelmann M. Wirsing von König $\mathrm{CH}$ : what to do and what not to do in serological diagnosis of pertussis: recommendations from EU reference laboratories. Eur J Clin Microbiol Infect Dis. 2011;30(3):307-12.

15. Versteegh FG, Mertens PL, de Melker HE, Roord JJ, Schellekens JF, Teunis PF. Age-specific long-term course of IgG antibodies to pertussis toxin after 
symptomatic infection with Bordetella pertussis. Epidemiol Infect. 2005;133(4):737-48.

16. de Melker HE, Versteegh FG, Conyn-Van Spaendonck MA, Elvers LH, Berbers GA, van Der Zee A, Schellekens JF. Specificity and sensitivity of high levels of immunoglobulin $G$ antibodies against pertussis toxin in a single serum sample for diagnosis of infection with Bordetella pertussis. J Clin Microbiol. 2000;38(2):800-6.

17. Guiso N, Liese J, Plotkin S. The Global Pertussis Initiative: meeting report from the fourth regional roundtable meeting, France, April 14-15, 2010. Hum Vaccin. 2011;7(4):481-8.

18. Guiso N, Wirsing von König C-H, Forsyth K, Tan T, Plotkin SA. The Global Pertussis Initiative: report from a round table meeting to discuss the epidemiology and detection of pertussis, Paris, France, 2010. Vaccine. 2011;29(6):1115-21.

19. Dalby T, Andersen PH, Hoffmann S: Epidemiology of pertussis in Denmark, 1995 to 2013. Euro surveillance : bulletin Europeen sur les maladies transmissibles $=$ European communicable disease bulletin 2016, 21(36).

20. Dalby T, Linneberg A, Krogfelt K. Seroprevalence of whooping cough among Danish adults. Clin Microbiol Infect. 2011;17:S282.

21. Dalby T, Harboe ZB, Krogfelt KA. Seroprevalence of pertussis among Danish patients with cough of unknown etiology. Clin Vaccine Immunol. 2010;17(12):2016-23.

22. He Q, Arvilommi H, Viljanen MK, Mertsola J. Outcomes of Bordetella infections in vaccinated children: effects of bacterial number in the nasopharynx and patient age. Clin Diagn Lab Immunol. 1999;6(4):534-6.

23. He Q, Viljanen MK, Nikkari S, Lyytikäinen R, Mertsola J. Outcomes of Bordetella pertussis infection in different age groups of an immunized population. J Infect Dis. 1994;170(4):873-7.

24. Tran Minh NN, He Q, Edelman K, Olander RM, Viljanen MK, Arvilommi H, Mertsola J. Cell-mediated immune responses to antigens of Bordetella pertussis and protection against pertussis in school children. Pediatr Infect Dis J. 1999;18(4):366-70.

25. He Q, Schmidt-Schläpfer G, Just M, Matter HC, Nikkari S, Viljanen MK, Mertsola J. Impact of polymerase chain reaction on clinical pertussis research: Finnish and Swiss experiences. J Infect Dis. 1996;174(6):1288-95.

26. He Q, Viljanen MK, Arvilommi H, Aittanen B, Mertsola J. Whooping cough caused by Bordetella pertussis and Bordetella parapertussis in an immunized population. JAMA. 1998;280(7):635-7.

27. Aase A, Herstad TK, Merino S, Brandsdal KT, Berdal BP, Aleksandersen EM, Aaberge IS. Opsonophagocytic activity and other serological indications of Bordetella pertussis infection in military recruits in Norway. Clin Vaccine Immunol. 2007;14(7): 855-62.

28. Advani A, Donnelly D, Gustafsson L, Hallander HO. Changes of the Swedish Bordetella pertussis population in incidence peaks during an acellular pertussis vaccine period between 1997 and 2004. APMIS. 2007;115(4):299-310.

29. Carlsson R-M, Trollfors B. Control of pertussis-lessons learnt from a 10-year surveillance programme in Sweden. Vaccine. 2009;27(42):5709-18.

30. Gustafsson L, Hessel L, Storsaeter J, Olin P. Longterm follow-up of Swedish children vaccinated with acellular pertussis vaccines at 3,5 , and 12 months of age indicates the need for a booster dose at 5 to 7 years of age. Pediatrics. 2006;118(3):978-84.

31. Hallander HO, Andersson M, Gustafsson L, Ljungman M, Netterlid E. Seroprevalence of pertussis antitoxin (anti-PT) in Sweden before and 10 years after the introduction of a universal childhood pertussis vaccination program. APMIS. 2009;117(12):912-22.

32. Folkhlsomyndigheten: Pertussis surveillance in Sweden. https://www.folkhalsomyndigheten.se/ contentassets/cd49fff196f44e6a8db234ffb9da8b80/ pertussis-surveillance-sweden-twenty-first-report19071.pdf. Accessed April 2021. 2018.

33. Statens Serum Institut.: Childhood vaccination program. https://en.ssi.dk/vaccination/the-danishchildhood-vaccination-programme. Accessed March 2021. 2019.

34. European Centers for Disease Prevention and Control.: Pertussis: Recommended vaccinations. https:// vaccine-schedule.ecdc.europa.eu/Scheduler/ByDise ase? SelectedDiseaseId=3\&SelectedCountryIdByDise ase $=-1$. Accessed August 2020 .

35. Frühwirth M, Neher C, Schmidt-Schläpfer G, Allerberger F. Bordetella pertussis and Bordetella parapertussis infection in an Austrian pediatric outpatient clinic. Wien Klin Wochenschr. 2002;114(10-11): 377-82.

36. Mahieu L, De Schrijver K, Van den Branden D, Boeckx H, Mahieu H, Wojciechowski M. Epidemiology of pertussis in children of Flanders Belgium: can healthcare professionals be involved in the infection? Acta Clin Belg. 2014;69(2):104-10. 
37. Huygen K, Rodeghiero C, Govaerts D, Leroux-Roels I, Melin P, Reynders M, Van Der Meeren S, Van Den Wijngaert S, Pierard D. Bordetella pertussis seroprevalence in Belgian adults aged 20-39 years, 2012. Epidemiol Infect. 2013;142(4):724-8.

38. Caboré RN, Piérard D, Huygen K: A Belgian serosurveillance/seroprevalence study of diphtheria, tetanus and pertussis using a luminex xMAP technology-based pentaplex. Vaccines 2016, 4(2).

39. Lasserre A, Laurent E, Turbelin C, Hanslik T, Blanchon T, Guiso N: Pertussis incidence among adolescents and adults surveyed in general practices in the Paris area, France, May 2008 to March 2009. Euro surveillance : bulletin Europeen sur les maladies transmissibles $=$ European communicable disease bulletin 2011, 16(5).

40. Bonmarin I, Poujol I, Levy-Bruhl D: Nosocomial infections and community clusters of pertussis in France, 2000-2005. Euro surveillance : bulletin Europeen sur les maladies transmissibles = European communicable disease bulletin 2007, 12(11): E11-12.

41. Gavazzi G, Pinquier D, Gaillat J, Gallais JL, Guiso N. Pertussis incidence in older individuals: results from the French EPICOQSEN study. Eur Geriatric Med. 2017;8:S35.

42. Gehanno JF, Pestel-Caron M, Nouvellon M, Caillard JF. Nosocomial pertussis in healthcare workers from a pediatric emergency unit in France. Infect Control Hosp Epidemiol. 1999;20(8):549-52.

43. Guiso N, Gallais JL, Gavazzi G, Pinquier D, Gaillat J. Incidence of pertussis in subjects aged 50years and older in France in 2013-2014. Medecine et maladies infectieuses. 2018;48(1):30-6.

44. Parent I, Gilberg S, Njamkepo E, Partouche H, Gueirard P, Schlumberger M, Guiso N: Prevalence of pertussis infection in adults with a persistent cough in a French area with high vaccine coverage. In: 41st Annual Meeting of the Interscience Conference on Antimicrobial Agents and Chemotherapy. vol. $41 ; 2001$.

45. Gilberg S, Njamkepo E, Du Châtelet IP, Partouche H, Gueirard P, Ghasarossian C, Schlumberger M, Guiso N. Evidence of Bordetella pertussis infection in adults presenting with persistent cough in a french area with very high whole-cell vaccine coverage. J Infect Dis. 2002;186(3):415-8.

46. Launay $O$, Toneatti $C$, Bernède $C$, Njamkepo $E$, Petitprez K, Leblond A, Larnaudie S, Goujon C, Ungeheuer MN, Ajana F, et al. Antibodies to tetanus, diphtheria and pertussis among healthy adults vaccinated according to the French vaccination recommendations. Hum Vaccin. 2009;5(5):341-6.
47. Liese JG, Renner C, Stojanov S, Belohradsky BH. Clinical and epidemiological picture of $B$ pertussis and $B$ parapertussis infections after introduction of acellular pertussis vaccines. Arch Dis Child. 2003;88(8):684-7.

48. Mancuso JD, Snyder A, Stigers J, Ortman B, Aldous W, Whoolery T, Deye G, Bradley K. Pertussis outbreak in a US military community: Kaiserslautern, Germany, April-June 2005. Clin Infect Dis. 2007;45(11):1476-8.

49. Finger $\mathrm{H}$, Wirsing von König $\mathrm{CH}$, Tacken $\mathrm{A}$, Wassilak SG. The epidemiological situation of pertussis in the Federal Republic of Germany. Dev Biol Standard. 1991;73:343-55.

50. Sin MA, Zenke R, Rönckendorf R, Littmann M, Jorgensen $\mathrm{P}$, Hellenbrand W. Pertussis outbreak in primary and secondary schools in Ludwigslust, Germany demonstrating the role of waning immunity. Pediatr Infect Dis J. 2009;28(3):242-4.

51. Hellenbrand W, Beier D, Jensen E, Littmann M, Meyer C, Oppermann $\mathrm{H}$, Wirsing von König $\mathrm{CH}$, Reiter S. The epidemiology of pertussis in Germany: past and present. BMC Infect Dis. 2009;9:22.

52. Haller S, Dehnert M, Karagiannis I, Rieck T, Siffczyk C, Wichmann O, Poethko-Mueller C, Hellenbrand $W$. Effectiveness of routine and booster pertussis vaccination in children and adolescents, federal state of Brandenburg, Germany, 2002-2012. Pediatr Infect Dis J. 2015;34(5):513-9.

53. Ryan A, Cullen L, Barret AS, Bourke S, Grogan J, Murray A, Cotter S, O'Hora A, Breslin A. Pertussis outbreak in a well vaccinated community in co. Leitrim Irish J Med Sci. 2011;180(6):S216.

54. Grogan JA, Logan C, O'Leary J, Rush R, O'Sullivan N. Real-time PCR-based detection of Bordetella pertussis and Bordetella parapertussis in an Irish paediatric population. J Med Microbiol. 2011;60(Pt 6): 722-9.

55. Hübschen JM, Charpentier E, Weicherding P, Muller CP. IgG antibody prevalence suggests high immunization needs in newcomers to Luxembourg, 2012. Vaccine. 2018;36(6):899-905.

56. Mertens PLJM, Borsboom GJJM, Richardus JH. A pertussis outbreak associated with social isolation among elderly nuns in a convent. Clin Infect Dis. 2007;44(2):266-8.

57. de Melker HE, Versteegh FGA, Schellekens JFP, Teunis PFM, Kretzschmar M. The incidence of Bordetella pertussis infections estimated in the population from a combination of serological surveys. J Infect. 2006;53(2):106-13. 
58. van der Maas NAT, Mooi FR, de Greeff SC, Berbers GAM, Spaendonck MAE-v, de Melker He. Pertussis in the Netherlands, is the current vaccination strategy sufficient to reduce disease burden in young infants? Vaccine. 2013;31(41):4541-7.

59. Van Der Maas NAT, De Greeff SC, Mooi FR, De Melker HE. Surveillance of pertussis in the netherlands: monitoring the impact of recent changes in the vaccination program. Pharmacoepidemiol Drug Saf. 2012;21:357.

60. de Greeff SC, Mooi FR, Schellekens JFP, de Melker HE. Impact of acellular pertussis preschool booster vaccination on disease burden of pertussis in The Netherlands. Pediatr Infect Dis J. 2008;27(3): 218-23.

61. de Melker HE, Conyn-van Spaendonck MA, Rümke HC, van Wijngaarden JK, Mooi FR, Schellekens JF. Pertussis in The Netherlands: an outbreak despite high levels of immunization with whole-cell vaccine. Emerg Infect Dis. 1997;3(2):175-8.

62. van der Lee $S$, Stoof $S P$, van Ravenhorst MB, van Gageldonk PGM, van der Maas NAT, Sanders EAM, Buisman A-M, Berbers GAM: Enhanced Bordetella pertussis acquisition rate in adolescents during the 2012 epidemic in the Netherlands and evidence for prolonged antibody persistence after infection. Euro surveillance : bulletin Europeen sur les maladies transmissibles $=$ European communicable disease bulletin 2017, 22(47).

63. de Greeff SC, de Melker HE, van Gageldonk PGM, Schellekens JFP, van der Klis FRM, Mollema L, Mooi FR, Berbers GAM. Seroprevalence of pertussis in The Netherlands: evidence for increased circulation of Bordetella pertussis. PLoS ONE. 2010;5(12):e14183.

64. Wymann MN, Richard J-L, Vidondo B, Heininger U. Prospective pertussis surveillance in Switzerland, 1991-2006. Vaccine. 2011;29(11):2058-65.

65. Amirthalingam G, Andrews N, Campbell H, Ribeiro S, Kara E, Donegan K, Fry NK, Miller E, Ramsay M. Effectiveness of maternal pertussis vaccination in England: an observational study. Lancet (London, England). 2014;384(9953):1521-8.

66. Bento AI, Riolo MA, Choi YH, King AA, Rohani P. Core pertussis transmission groups in England and Wales: a tale of two eras. Vaccine. 2018;36(9): 1160-6.

67. Nardone A, Pebody RG, Maple PAC, Andrews N, Gay NJ, Miller E. Sero-epidemiology of Bordetella pertussis in England and Wales. Vaccine. 2004;22(9-10):1314-9.

68. Amirthalingam G, Campbell H, Ribeiro S, Fry NK, Ramsay M, Miller E, Andrews N. Sustained effectiveness of the maternal pertussis immunization program in England 3 years following introduction. Clin Infect Dis. 2016;63(suppl 4):S236-43.

69. Campbell H, Amirthalingam G, Andrews N, Fry NK, George RC, Harrison TG, Miller E. Accelerating control of pertussis in England and Wales. Emerg Infect Dis. 2012;18(1):38-47.

70. Crabbe H, Saavedra-Campos $M$, Verlander NQ, Leonard A, Morris J, Wright A, Balasegaram S: Are pertussis cases reported too late for public health interventions? Retrospective analysis of cases in London and South East England, 2010 to 2015. Euro surveillance : bulletin Europeen sur les maladies transmissibles $=$ European communicable disease bulletin 2017, 22(29).

71. Wang K, Fry NK, Campbell H, Amirthalingam G, Harrison TG, Mant D, Harnden A. Whooping cough in school age children presenting with persistent cough in UK primary care after introduction of the preschool pertussis booster vaccination: prospective cohort study. BMJ (Clinical research ed). 2014;348: g3668.

72. Mitchell AA, Liddell KG, Criggie W. Adult pertussis in a general practice. Health Bull. 2000;58(1):34-7.

73. Miller E, Fleming DM, Ashworth LA, Mabbett DA, Vurdien JE, Elliott TS. Serological evidence of pertussis in patients presenting with cough in general practice in Birmingham. Commun Dis Public Health. 2000;3(2):132-4.

74. Wirsing von König CH, Postels-Multani S, Bock HL, Schmitt HJ. Pertussis in adults: frequency of transmission after household exposure. Lancet (London, England). 1995;346(8986):1326-9.

75. Oxford Vaccine Group: The UK Immunisation Schedule. https://vk.ovg.ox.ac.uk/vk/uk-schedule. Accessed Mar 21.

76. Choi YH, Campbell H, Amirthalingam G, van Hoek $\mathrm{AJ}$, Miller E. Investigating the pertussis resurgence in England and Wales, and options for future control. BMC Med. 2016;14(1):121.

77. Gancheva G, Pakov I, Levterova V, Doichinova T. Clinical and epidemiological features of pertussis cases in Pleven region. Probl Infect Parasitic Dis. 2017;45(2):36-41.

78. St Tsankova G, Ivanova E, Todorova T, Konstantinov R, Ermenlieva N, Draganova I. Epidemiological study of pertussis immunization effectiveness in varna region (2009-2014). J IMAB Annu Proc (Scientific Papers). 2016;22(2):1154-6.

79. Alexiev R, Todorova I, Hadjiiski K, Milanova A, Malchanova S, Demireva V, Nenkov P. Protection of 
the adults and adolescents against diphtheria, tetanus and whooping cough in Bulgaria. Probl Infect Parasitic Dis. 2009;37(1):20-4.

80. Fabiánová K, Benes C, Kríz B. A steady rise in incidence of pertussis since nineties in the Czech Republic. Epidemiologie, Mikrobiologie, Imunologie: Casopis Spolecnosti pro Epidemiologii a Mikrobiologii Ceske Lekarske Spolecnosti JE PURKYNE. 2010;59(1):25-33.

81. Maixnerová M. The 2001 serological survey in the Czech Republic-pertussis. Cent Eur J Public Health. 2003;11(Suppl):S17-22.

82. Jõgi $\mathrm{P}$, Oona $\mathrm{M}$, Toompere $\mathrm{K}$, Leedo $\mathrm{S}$, Epstein J, Lutsar I. Seroprevalence of IgG antibodies to pertussis toxin in children and adolescents in Estonia. Vaccine. 2014;32(41):5311-5.

83. Jõgi P, Oona M, Toompere K, Lutsar I. Estimated and reported incidence of pertussis in Estonian adults: a seroepidemiological study. Vaccine. 2015;33(38):4756-61.

84. Torzsa P, Devadiga R, Tafalla M. Seroprevalence of Bordetella pertussis antibodies in adults in Hungary: results of an epidemiological cross-sectional study. BMC Infect Dis. 2017;17(1):242.

85. Gama de Sousa S, Barros H. Pertussis in Portugaltime for a new strategy. Rev Port Pneumol. 2010;16(4):573-88.

86. Zieliński A, Rosińska M, Czarkowski M, Rudowska J. The effectiveness of vaccination with whole-cell pertussis vaccine by age group in Poland 1996-2001. Scand J Infect Dis. 2004;36(2):114-8.

87. Socan M, Prosenc K, Vegnuti M. Seroprevalence of IgG antibodies to pertussis toxin in the Slovene population. Wien Klin Wochenschr. 2006;118(11-12):336-40.

88. National Institute of Public Health, National Institute of Hygiene P: Mandatory vaccinations in Poland-history and rationale. https://szczepienia. pzh.gov.pl/en/stories/mandatory-vaccinations-inpoland/. Accessed Mar 2021. 2020.

89. Nitsch-Osuch A, Kuchar E, Modrzejewska G, Pirogowicz I, Zycinska K, Wardyn K. Epidemiology of pertussis in an urban region of Poland: time for a booster for adolescents and adults. Adv Exp Med Biol. 2013;755:203-12.

90. Stefanoff P, Paradowska-Stankiewicz IA, Lipke M, Karasek E, Rastawicki W, Zasada A, Samuels S, Czajka H, Pebody RG. Incidence of pertussis in patients of general practitioners in Poland. Epidemiol Infect. 2013;142(4):714-23.
91. Gzyl A, Augustynowicz E, Rabczenko D, Gniadek G, Slusarczyk J. Pertussis in Poland. Int J Epidemiol. 2004;33(2):358-65.

92. Paradowska-Stankiewicz I, Rudowska J. Pertussis in Poland in 2011. Przegl Epidemiol. 2013;67(2): 199-201 ((319-121)).

93. Paradowska-Stankiewicz I, Rudowska J. Pertussis in Poland in 2012. Przegl Epidemiol. 2014;68(2):205-7 ((325-207)).

94. Paradowska-Stankiewicz I, Rudowska J. Pertussis in Poland in 2013. Przegl Epidemiol. 2015;69(4):745-7 ((885-747)).

95. Paradowska-Stankiewicz I, Rudowska J. Pertussis in Poland in 2014. Przegl Epidemiol. 2016;70(3): 327-32.

96. Jõgi P, Oona M, Kaart T, Toompere K, Maskina T, Koort I, Rätsep A, Lutsar I. Pertussis and parapertussis in children and adults with a persistent cough: an observational study. Infection. 2018;46(1):83-91.

97. Grgic-Vitek M, Klavs I, Kraigher A. Re-emergence of pertussis in Slovenia: time to change immunization policy. Vaccine. 2008;26(15):1874-8.

98. Chlibek R, Smetana J, Sosovickova R, Fabianova K, Zavadilova J, Dite P, Gal P, Naplava P, Lzicarova D. Seroepidemiology of whooping cough in the Czech Republic: estimates of incidence of infection in adults. Public Health. 2017;150:77-83.

99. Theodoridou M, Hadjipanagis A, Persianis N, Makri S, Hadjichristodoulou C: Pertussis outbreak detected by active surveillance in Cyprus in 2003. Euro surveillance : bulletin Europeen sur les maladies transmissibles $=$ European communicable disease bulletin 2007, 12(5):E11-12.

100. Karabaxoglou D, Bakali E, Siasios P, Kaftantzi A, Dima E, Kansouzidou A. Pertussis remains a health problem. Clin Microbiol Infect. 2009;15:S597.

101. Polyzou A, Pournaras S, Dafni U, Sofianou D, Christeli E, Patrinos S, Tsakris A. Sero epidemiology of Bordetella pertussis immune responses in a healthy population in northern Greece. J Clin Lab Anal. 2004;18(3):211-4.

102. Giammanco A, Chiarini A, Stroffolini T, De Mattia D, Chiaramonte M, Moschen ME, Mura I, Rigo G, Taormina S, Sarzana A. Seroepidemiology of pertussis in Italy. Rev Infect Dis. 1991;13(6):1216-20.

103. Antico A, Fabozzi F, Scipiotti C: Pertussis in adults. A study in an Italian population with chronic cough. Monaldi archives for chest disease = 
Archivio Monaldi per le malattie del torace 2002, 57(5-6):247-252.

104. Rota MC, Ausiello CM, D'Amelio R, Cassone A, Giammanco A, Molica C, Lande R, Greco D, Salmaso S. Prevalence of markers of exposure to Bordetella pertussis among Italian young adults. Clin Infect Dis. 1998;26(2):297-302.

105. Fedele G, Carollo M, Palazzo R, Stefanelli P, Pandolfi E, Gesualdo F, Tozzi AE, Carsetti R, Villani A, Nicolai A, et al. Parents as source of pertussis transmission in hospitalized young infants. Infection. 2017;45(2):171-8.

106. Palazzo R, Carollo M, Fedele G, Rizzo C, Rota MC, Giammanco A, Iannazzo S, Ausiello CM. Evidence of increased circulation of Bordetella pertussis in the italian adult population from seroprevalence data (2012-2013). J Med Microbiol. 2016;65(7): 649-57.

107. Gonfiantini MV, Carloni E, Gesualdo F, Pandolfi E, Agricola E, Rizzuto E, Iannazzo S, Ciofi Degli Atti ML, Villani A, Tozzi AE: Epidemiology of pertussis in Italy: disease trends over the last century. Euro surveillance : bulletin Europeen sur les maladies transmissibles $=$ European communicable disease bulletin 2014, 19(40):20921.

108. Ciofi Degli Atti ML, Salmaso S, Bella A, Arigliani R, Gangemi M, Chiamenti G, Brusoni G, Tozzi AE. Pediatric sentinel surveillance of vaccine-preventable diseases in Italy. Pediatric Infect Dis J. 2002;21(8):763-8.

109. Del Prete R, Ronga L, Lestingi M, Addati G, Angelotti UF, Miragliotta G. Detection of atypical respiratory pathogens in patients with suspected lower respiratory tract infections in Apulia, Southern Italy. Minerva Pneumol. 2017;56(2):59-68.

110. Tafuri S, Gallone MS, Martinelli D, Prato R, Chironna $\mathrm{M}$, Germinario C. Report of a pertussis outbreak in a low coverage booster vaccination group of otherwise healthy children in Italy. BMC Infect Dis. 2013;13:541.

111. Godoy P, García-Cenoz M, Toledo D, Carmona G, Caylà JA, Alsedà M, Àlvarez J, Barrabeig I, Camps N, Plans P et al: Factors influencing the spread of pertussis in households: a prospective study, Catalonia and Navarre, Spain, 2012 to 2013. Euro surveillance : bulletin Europeen sur les maladies transmissibles = European communicable disease bulletin 2016, 21(45).

112. Miguez Santiyan A, Ferrer Estrems R, Chover Lara JL, Alberola Enguidanos J, Nogueira Coito JM, Salazar Cifre A: Early intervention in pertussis outbreak with high attack rate in cohort of adolescents with complete acellular pertussis vaccination in
Valencia, Spain, April to May 2015. Euro surveillance : bulletin Europeen sur les maladies transmissibles $=$ European communicable disease bulletin 2015, 20(27).

113. Sala Farré MR, Arias Varela C, Recasens Recasens A, Pérez Jové J, Balius Fort E, Simó Sanahuja M. Pertussis epidemic in 2011, region of Vallès (Catalonia, Spain). Clin Microbiol Infect. 2012;18:224-5.

114. Sizaire V, Garrido-Estepa M, Masa-Calles J, Martinez de Aragon MV: Increase of pertussis incidence in 2010 to 2012 after 12 years of low circulation in Spain. Euro surveillance : bulletin Europeen sur les maladies transmissibles $=$ European communicable disease bulletin 2014, 19(32).

115. Vera I, García-Comas L, Ordobás M, Gutiérrez A, Sanz JC, Barranco D: Incidence trends in pertussis in the Autonomous Region of Madrid, Spain: 1982-2005. Euro surveillance : bulletin Europeen sur les maladies transmissibles = European communicable disease bulletin 2007, 12(9):E7-8.

116. Crespo I, Cardeñosa N, Godoy P, Carmona G, Sala MR, Barrabeig I, Alvarez J, Minguel S, Camps N, Caylà J, et al. Epidemiology of pertussis in a country with high vaccination coverage. Vaccine. 2011;29(25):4244-8.

117. Brugueras S, Rius C, Millet J-P, Casals M, Caylà JA. Does the economic recession influence the incidence of pertussis in a cosmopolitan European city? BMC Public Health. 2019;19(1):144.

118. Puig-Barberà J, Díez-Domingo J, Pastor-Villalba E, Garcia-Lomas J, Huertas-Zarco I, Pérez-Hoyos S. Pertussis in adults with persistent cough: a prospective follow up study in primary care. Procedia Vaccinol. 2009;1(1):73-80.

119. Sala-Farré M-R, Arias-Varela C, Recasens-Recasens A, Simó-Sanahuja M, Muñoz-Almagro C, Pérez-Jové J. Pertussis epidemic despite high levels of vaccination coverage with acellular pertussis vaccine. Enferm Infecc Microbiol Clin. 2015;33(1):27-31.

120. Crespo I, Broner S, Soldevila N, Martínez A, Godoy P, Sala-Farré M-R, Company M, Rius C, Domínguez A. Group Of Catalonia TPW: characteristics of pertussis outbreaks in Catalonia, Spain, 1997 to 2010. Hum Vaccin Immunother. 2015;11(1):231-5.

121. Domínguez A, Vidal J, Plans P, Salleras L. The seroepidemiology of $B$ pertussis infection in Catalonia Spain. Epidemiol Infect. 2001;126(2):205-10.

122. Fernández-Cano MI, Armadans Gil L, Martínez Gómez X, Campins Martí M. Incidence of whooping cough in Spain (1997-2010): an underreported disease. Eur J Pediatr. 2014;173(6):721-6. 
123. González-Escalada A, García-García L, Viguera-Ester P, Marín-García P, García J, Gil-de-Miguel A, GilPrieto R: Seroprevalence of antibodies against measles, rubella, mumps, varicella-zoster, and $\mathrm{B}$. Pertussis in young adults of Madrid, Spain. Hum Vaccine Immunother 2013, 9(9):1918-1925.

124. de Juanes J-R, Gil A, González A, Arrazola M-P, SanMartín M, Esteban J. Seroprevalence of pertussis antibody among health care personnel in Spain. Eur J Epidemiol. 2004;19(1):69-72.

125. Urbiztondo L, Broner S, Costa J, Rocamora L, Bayas JM, Campins M, Esteve M, Borras E, Domínguez A, For The Study Of The Immune Status In Health Care TWG: Seroprevalence study of B. pertussis infection in health care workers in Catalonia, Spain. Hum Vaccines Immunother 2015, 11(1):293-297.

125. Rodríguez de la Pinta ML, Castro Lareo MI, Ramon Torrell JM, García de Lomas J, Devadiga R, Reyes J, McCoig C, Tafalla M, García-Corbeira P: Seroprevalence of pertussis amongst healthcare professionals in Spain. Vaccine 2016, 34(8):1109-1114.

127. Diez-Domingo J, Ballester A, Baldó J-M, Planelles $\mathrm{M}-\mathrm{V}$, Villarroya JV, Alvarez T, Carmen Peidró M, Calero P, Garcés MD, Sorribes I, et al. Incidence of pertussis in persons $<$ or $=15$ years of age in Valencia, Spain: seroprevalence of antibodies to pertussis toxin (PT) in children, adolescents and adults. J Infect. $2004 ; 49(3): 242-7$.

128. Herzig P, Hartmann C, Fischer D, Weil J, von Kries R, Giani G, Schroten H. Wirsing von König $\mathrm{CH}$ : Pertussis complications in Germany-3 years of hospital-based surveillance during the introduction of acellular vaccines. Infection. 1998;26(4):227-31.

129. Kazantzi MS, Prezerakou A, Kalamitsou SN, Ilia S, Kalabalikis PK, Papadatos J, Sdougka MM, Briassoulis G, Tsolia MN. Characteristics of Bordetella pertussis infection among infantsand children admitted to paediatric intensive care units in Greece: a multicentre, 11-year study. J Paediatr Child Health. 2017;53(3):257-62.

130. Howell F, Jennings S. The epidemiology of pertussis in the Republic of Ireland. Commun Dis Rep CDR Rev. 1992;2(3):R31-33.

131. Pezzotti P, Bellino S, Prestinaci F, Iacchini S, Lucaroni F, Camoni L, Barbieri MM, Ricciardi W, Stefanelli P, Rezza G. The impact of immunization programs on 10 vaccine preventable diseases in Italy: 1900-2015. Vaccine. 2018;36(11):1435-43.

132. de Melker HE, Schellekens JF, Neppelenbroek SE, Mooi FR, Rümke HC, Conyn-van Spaendonck MA. Reemergence of pertussis in the highly vaccinated population of the Netherlands: observations on surveillance data. Emerg Infect Dis. 2000;6(4): 348-57.

133. Mertens PL, Stals FS, Schellekens JF, Houben AW, Huisman J. An epidemic of pertussis among elderly people in a religious institution in The Netherlands. Eur J Clin Microbiol Infect Dis. 1999;18(4):242-7.

134. van der Maas NAT, Hoes J, Sanders EAM, de Melker HE. Severe underestimation of pertussis related hospitalizations and deaths in the Netherlands: a capture-recapture analysis. Vaccine. 2017;35(33): 4162-6.

135. Oliveira SM, Gonçalves-Pinho M, Freitas A, Guimarães $\mathrm{H}$, Azevedo I. Trends and costs of pertussis hospitalizations in Portugal, 2000 to 2015: from 0 to 95 years old. Infect Dis (London, England). 2018;50(8):625-33.

136. Gil A, Oyagüez I, Carrasco P, González A. Hospital admissions for pertussis in Spain, 1995-1998. Vaccine. 2001;19(32):4791-4.

137. Bodimeade CG, Radcliffe R, Perera N, Pearce D. Evaluationof treatment and outcomes in paediatric patients with whooping cough (Bordatella pertussis) at a hospital trust from 2012-2017. Arch Dis Child. 2019;104:A143-4.

138. Miller E, Vurdien JE, White JM. The epidemiology of pertussis in England and Wales. Commun Dis Rep CDR Rev. 1992;2(13):R152-154.

139. Robinson S, Harvey C, Westrope C, Speggiorin S, Gratrix M, Faulkner G, Peek G. Mobile ECMO of neonatal, paediatric \& adult patients: the glenfield experience. Intensive Care Med. 2013;39:S47.

140. Mokhort H, Kovalchuk A, Sokolovska O, Higgs S. Contribution of Vaccination to the Reduction of Infectious Mortality in Ukraine in the Second Half of the 20th and Early 21st Century: a Comparative Population-Based Study of the Dynamics and Structure of Infectious Mortality and Incidence. Viral Immunol. 2018;31(10):695-707.

141. Celentano LP, Massari M, Paramatti D, Salmaso S, Tozzi AE. Resurgence of pertussis in Europe. Pediatr Infect Dis J. 2005;24(9):761-5.

142. Tozzi AE, Pandolfi E, Celentano LP, Massari M, Salmaso S, Ciofi degli Atti ML. Comparison of pertussis surveillance systems in Europe. Vaccine. 2007;25(2):291-7.

143. European Centers for Disease Prevention and Control.: Pertussis. Annual Epidemiological Report for 2018. https://www.ecdc.europa.eu/sites/default/ files/documents/AER_for_2018_pertussis.pdf. Accessed Mar 2021. 
144. Sheikh S, Biundo E, Courcier S, Damm O, Launay O, Maes E, Marcos C, Matthews S, Meijer C, Poscia A, et al. A report on the status of vaccination in Europe. Vaccine. 2018;36(33):4979-92.

145. Lévy-Bruhl D, Fonteneau L, Vaux S, Barret AS, Antona D, Bonmarin I, Che D, Quelet S, Coignard B: Assessment of the impact of the extension of vaccination mandates on vaccine coverage after 1 year, France, 2019. Euro Surveill 2019, 24(26).

146. Broder KR, Cortese MM, Iskander JK, Kretsinger K, Slade BA, Brown KH, Mijalski CM, Tiwari T, Weston EJ, Cohn AC et al: Preventing tetanus, diphtheria, and pertussis among adolescents: use of tetanus toxoid, reduced diphtheria toxoid and acellular pertussis vaccines recommendations of the Advisory Committee on Immunization Practices (ACIP). MMWR Recommendations and reports : Morbidity and mortality weekly report Recommendations and reports 2006, 55(Rr-3):1-34.

147. Zepp F, Heininger U, Mertsola J, Bernatowska E, Guiso N, Roord J, Tozzi AE, Van Damme P. Rationale for pertussis booster vaccination throughout life in Europe. Lancet Infect Dis. 2011;11(7):557-70.

148. Quinn HE, McIntyre PB. The impact of adolescent pertussis immunization, 2004-2009: lessons from Australia. Bull World Health Organ. 2011;89(9): 666-74.

149. Skoff TH, Cohn AC, Clark TA, Messonnier NE, Martin SW. Early Impact of the US Tdap vaccination program on pertussis trends. Arch Pediatr Adolesc Med. 2012;166(4):344-9.

150. Klein NP, Bartlett J, Fireman B, Baxter R. Waning Tdap effectiveness in adolescents. Pediatrics. 2016;137(3):e20153326.

151. Baxter R, Bartlett J, Rowhani-Rahbar A, Fireman B, Klein NP. Effectiveness of pertussis vaccines for adolescents and adults: case-control study. BMJ. 2013;347:f4249.

152. Acosta AM, DeBolt C, Tasslimi A, Lewis M, Stewart LK, Misegades LK, Messonnier NE, Clark TA, Martin SW, Patel M. Tdap vaccine effectiveness in adolescents during the 2012 Washington State pertussis epidemic. Pediatrics. 2015;135(6):981-9.

153. Chit A, Zivaripiran $H$, Shin T, Lee JKH, Tomovici A, Macina D, Johnson DR, Decker MD, Wu J. Acellular pertussis vaccines effectiveness over time: A systematic review, meta-analysis and modeling study. PLoS ONE. 2018;13(6):e0197970.
154. Bonmarin I, Bouraoui L, Guiso N, Levy-Bruhl D. Pertussis: data collection and vaccinal strategy. Med Mal Infect. 2009;39(5):271-7.

155. Gavazzi G, Esposito S, Franco E, Gil De Miguel A, Hardt R, Kassianos G, Bertrand I, López Trigo JA. Review of burden of vaccine-preventable diseases in seniors in Europe. Eur Geriatric Med. 2016;7: S173-4.

156. Forsyth K, Plotkin S, Tan T, WirsingvonKönig $\mathrm{CH}$. Strategies to Decrease Pertussis Transmission to Infants. Pediatrics J. 2015;135(6):e1475-82.

157. Carrasquilla G, Porras A, Martinez S, DeAntonio R, Devadiga R, Caceres DC, Juliao P. Incidence and mortality of pertussis disease in infants $<12$ months of age following introduction of pertussis maternal universal mass vaccination in Bogotá, Colombia. Vaccine. 2020;38(46):7384-92.

158. Coudeville L, van Rie A, Andre P. Adult pertussis vaccination strategies and their impact on pertussis in the United States: evaluation of routine and targeted (cocoon) strategies. Epidemiol Infect. 2008;136(5):604-20.

159. Forsyth KD, Tan T, Vonkönig C-HW, Heininger U, Chitkara AJ, Plotkin S: Recommendations to control pertussis prioritized relative to economies: A Global Pertussis Initiative update. Vaccine 2018, 36(48): 7270-7275

160. Kandeil W, van den Ende C, Bunge EM, Jenkins VA, Ceregido MA, Guignard A. A systematic review of the burden of pertussis disease in infants and the effectiveness of maternal immunization against pertussis. Expert Rev Vaccines. 2020;19(7):621-38.

161. Dewan KK, Linz B, DeRocco SE, Harvill ET: Acellular pertussis vaccine components: today and tomorrow. Vaccines (Basel) 2020, 8(2).

162. Liu BC, McIntyre P, Kaldor JM, Quinn HE, Ridda I, Banks E. Pertussis in older adults: prospective study of risk factors and morbidity. Clin Infect Dis. 2012;55(11):1450-6.

163. Agger WA, Naik RM. How should we approach adolescent and adult pertussis? WMJ. 2006;105(1): 47-51.

164. Rothstein E, Edwards K. Health burden of pertussis in adolescents and adults. Pediatr Infect Dis J. 2005;24(5 Suppl):S44-47. 
165. Torm S, Meriste S, Tamm E, Alusalu S, Järviste A, Lang K. Pertussis outbreak in a basic school in Estonia: description, contributing factors and vaccine effectiveness. Scand J Infect Dis. 2005;37(9): 664-8.

166. Paradowska-Stankiewicz I, Rudowska J. Pertussis in Poland in 2015. Przegl Epidemiol. 2017;71(4): 481-5.

\section{Publisher's Note}

Springer Nature remains neutral with regard to jurisdictional claims in published maps and institutional affiliations" (in PDF at the end of the article below the references; in XML as a back matter article note). 